MS. XIAOYU ZHOU (Orcid ID : 0000-0003-0798-6493)

DR. RYOJI TANAKA (Orcid ID : 0000-0002-7537-255X)

Article type : Original Article

\title{
A Method to Suppress Isobaric and Polyatomic Interferences for Measurements of Highly Siderophile Elements in Desilicified Geological Samples
}

Xiaoyu Zhou*, Ryoji Tanaka, Masahiro Yamanaka, Chie Sakaguchi and Eizo Nakamura

The Pheasant Memorial Laboratory for Geochemistry and Cosmochemistry, Institute for Planetary Materials, Okayama University, Misasa, Tottori, 682-0193, Japan

*Corresponding author. e-mail: zhouxiaoyu@ @s.okayama-u.ac.jp

\begin{abstract}
Sample decomposition using inverse aqua regia at elevated temperatures and pressures (e.g., Carius tube or high pressure asher) is the most common method used to extract highly siderophile elements (HSEs: Ru, $\mathrm{Rh}, \mathrm{Pd}, \mathrm{Re}, \mathrm{Os}, \mathrm{Ir}, \mathrm{Pt}$ and $\mathrm{Au}$ ) from geological samples. Recently, it has been recognised that additional HF-desilicification is necessary to better recover HSEs, potentially contained within silicate or oxide minerals in mafic samples, which cannot be dissolved solely by inverse aqua regia. However, the abundance of interfering elements tends to increase in the eluent when conventional ion-exchange purification procedures are applied to desilicified samples. In this study, we developed an improved purification method to determine HSEs in desilicified samples. This method enables the reduction of the ratios of isobaric and polyatomic interferences, relative to the measured intensities of HSE isotope masses, to less than a few hundred parts per million. Furthermore, the total procedural blanks are either comparable This article has been accepted for publication and undergone full peer review but has not been through the copyediting, typesetting, pagination and proofreading process, which may lead to differences between this version and the Version of Record. Please cite this article as doi: $10.1111 /$ ggr.12280

This article is protected by copyright. All rights reserved.
\end{abstract}


to or lower than conventional methods. Thus, this method allows accurate and precise HSE measurements in mafic and ultramafic geological samples, without the need for interference corrections. Moreover, the problem of increased interfering elements, such as $\mathrm{Zr}$ for $\mathrm{Pd}$, and $\mathrm{Cr}$ for $\mathrm{Ru}$, is circumvented for the desilicified samples.

Keywords: highly siderophile elements, desilicification, isotope dilution method, high resolution ICP-MS, N-TIMS.

\section{Received 29 Dec 18 - Accepted 27 Apr 19}

Highly siderophile elements (HSEs) are used as important geochemical tracers for understanding fundamental processes such as planetary differentiation, core segregation, late accretion, core-mantle interaction, meteorite impacts, metallogenesis and others. (e.g., Brandon et al. 1999, 2006, Becker et al. 2001, 2006, Horan et al. 2003, Brandon and Walker 2005, Dale et al. 2012a, Barnes and Ripley 2016, Becker and Dale 2016, Day et al. 2016a, Gannoun et al. 2016). Although numerous analytical methods for HSEs have been developed, further improvements in purification procedures have been reported in recent years that allow the collection of highly accurate and precise ICP-MS and TIMS data (e.g., Jarvis et al. 1997a, Rehkämper and Halliday 1997, Ely et al. 1999, Pearson and Woodland 2000, Meisel and Moser 2004a, b, Qi et al. 2004, Shinotsuka and Suzuki 2007, Savard et al. 2010, Fischer-Gödde et al. 2011, Ishikawa et al. 2014, Li et al. 2014, 2015, Chu et al. 2015a, Day et al. 2016b, Ren et al. 2016). Quantitative measurements of HSEs are hampered by the following: (1) extremely low abundances (typically $<$ a few $\mathrm{ng} \mathrm{g}^{-1}$ ) in terrestrial rock samples, (2) achieving full sample-spike equilibrium without losing the volatile $\mathrm{OsO}_{4}$, (3) sample heterogeneity caused by the nugget effect, (4) relatively high contribution of procedural blanks relative to the low HSE mass fractions, and (5) incomplete removal of matrix and isobaric and polyatomic interfering elements. To overcome these difficulties, the Carius tube (CT) method, using inverse aqua regia, coupled with the isotope dilution method was employed by most laboratories (e.g., Becker et al. 2006, Luguet et al.

This article is protected by copyright. All rights reserved. 
2007, Shinotsuka and Suzuki 2007, Puchtel et al. 2008, Qi and Zhou 2008, Ishikawa et al. 2014, Li et al. 2014). However, one major potential limitation of the CT method is that inverse aqua regia cannot dissolve silicates and oxide minerals containing a small fraction of HSEs. To obtain complete or high recovery of HSEs from geological samples using the CT method, a desilicification step is necessary. Such as step was undertaken by adding HF before or after inverse aqua regia decomposition, and its effectiveness has been reported for mafic rock samples (Dale et al. 2009, Meisel et al. 2009, Ishikawa et al. 2014, Li et al. 2015, Day et al. 2016b). However, some analytical problems arise when applying desilicification. Day et al. (2016b) reported that the abundances of interfering elements in the desilicified sample elution were much higher than in the non-desilicified sample elution using an anion-exchange purification procedure. They also pointed out that HF treatment after CT decomposition increased blanks and modified Re/Os and Pt/Os concentration ratios in some analysed basalts. Ishikawa et al. (2014) reported that there were no distinguishable differences for interfering elements and blanks between with and without desilicification procedures. Moreover, they discussed the potential problem of Cr oxide for Ru measurement. To effectively suppress interfering elements in desilicified geological samples, the improvement of the purification procedure is a prerequisite for accurate HSE measurement results.

To separate HSEs from other elements in geological samples, previous studies have employed either an anion exchange resin (Jarvis et al. 1997b, Pearson and Woodland 2000, Meisel et al. 2001, Ishikawa et al. 2014, Chu et al. 2015a) or a cation exchange resin (Jarvis et al. 1997a, Ely et al. 1999, Meisel et al. 2003a, 2004a, b, Shinotsuka and Suzuki 2007, Fischer-Gödde et al. 2011, Li et al. 2014). Cation exchange resin has the advantage of a higher recovery of HSEs, when compared with anion exchange resin, but a larger volume of resin is required. The matrix elements can be removed using both types of resin. However, the aforementioned ion-exchange chromatographic methods are, unable to completely separate interfering elements (e.g., Cr, Y, Zr, Hf, Cd, Mo and W) from HSEs for subsequent mass spectrometric measurements. Therefore, several studies employed one or more purification steps (Shinotsuka and Suzuki 2007, Ishikawa et al. 2014, Li et al. 2014, Chu et al. 2015a). In geological samples, the concentrations of interfering 
elements are considerably higher than those of HSEs, making it difficult to sufficiently purify HSEs to avoid interferences. Therefore, isobaric and polyatomic interference corrections have been generally applied during mass spectrometric measurements (e.g., Ely et al. 1999, Pearson and Woodland 2000, Shinotsuka and Suzuki 2007, Ishikawa et al. 2014, Li et al. 2014).

In this study, we present a newly developed purification method for HSEs from geological samples using a cation exchange resin (AG50W-X12) and three additional ion-exchange purification steps, following CT decomposition, Os extraction, and HF desilicification. This method allows for the measurement of HSEs without interference corrections for geological samples. Using this improved method, the $\mathrm{Ru}, \mathrm{Pd}, \mathrm{Re}, \mathrm{Ir}, \mathrm{Pt}$ and Os mass fractions and ${ }^{187} \mathrm{Os} /{ }^{188} \mathrm{Os}$ ratios of geological RMs in ultramafic to mafic compositions were evaluated.

\section{Experimental section}

All experiments in this study were performed at the Pheasant Memorial Laboratory for Geochemistry and Cosmochemistry (PML), Institute for Planetary Materials, Okayama University at Misasa, Japan.

\section{Reagents and materials}

High purity water $(\geq 18.2 \mathrm{M} \Omega \mathrm{cm}$ ) was prepared using a Milli-Q system (Merck Millipore, Darmstadt, Germany). For the sample decomposition and purification, TAMAPURE-AA-10 grade 38\% HF and 68\% $\mathrm{HNO}_{3}$, TAMAPURE-AA-100 grade 30\% $\mathrm{HCl}$ (Tama Chemicals, Kawasaki, Japan), infinity pure-grade $\mathrm{CCl}_{4}$ (Wako Pure Chemical Industries, Osaka, Japan), and analytical grade 48\% $\mathrm{HBr}$ (Kanto Chemical, Tokyo, Japan) were utilised. The HBr was further purified twice by distillation, as in Makishima and Nakamura (2001). We employed a HSE mixed spike solution containing ${ }^{101} \mathrm{Ru},{ }^{105} \mathrm{Pd},{ }^{185} \mathrm{Re},{ }^{189} \mathrm{Os},{ }^{191} \mathrm{Ir}$ and ${ }^{195} \mathrm{Pt}$ enriched isotopes prepared as described by Nakamura et al. (2003). The mass fractions of the HSE mixed spike solution were calibrated by the reverse isotope dilution method using the Precious

This article is protected by copyright. All rights reserved. 
Metals plasma standard solution from Specpure ${ }^{\circledR}$ (Alfa Aesar, Lancashire, UK; the certified concentrations: $100.0 \pm 0.5 \mu \mathrm{g} \mathrm{ml}^{-1}$ of Au, Ir, Os, Pd, Pt, Re, Rh and Ru, are directly traceable to the NIST SRMs). The geological RMs UB-N (serpentinite, CRPG), JP-1 (harzburgite, GSJ), TDB-1 (diabase, CCRMP) (Meisel et al. 2003b, Meisel and Moser 2004b), MUH-1 (harzburgite, IAG) and OKUM (komatiitic basalt, IAG) were analysed in this study. The ultramafic RMs UB-N and JP-1 from purchased batches were further pulverised in our laboratory. Of the five RMs, MUH-1 and OKUM are new ultramafic RMs prepared by IAGeo Limited, which have been distributed for interlaboratory comparisons of HSE and Os isotopic compositions (Meisel et al. 2013, Meisel and Horan 2016). The major and trace elements were already certified via IAGeo Limited (Burnham et al. 2010).

Powdered samples were decomposed with inverse aqua regia in a borosilicate CT $(2.5 \mathrm{~mm}$ thick and $20 \mathrm{~cm}$ long main body with $7 \mathrm{~cm}$ neck), similar to that described by Shirey and Walker (1995). Before decomposition, the CT was cleaned in detergent (TMSC, Tama Chemicals, Kawasaki, Japan), subsequently rinsed with water and a mixture of $9.5 \mathrm{~mol}^{-1} \mathrm{HCl}(4 \mathrm{ml})$ and $16 \mathrm{~mol} \mathrm{l}^{-1} \mathrm{HNO}_{3}(8 \mathrm{ml})$ was added. The CT was flame-sealed, and finally cleaned at $240{ }^{\circ} \mathrm{C}$ for $\sim 48 \mathrm{~h}$, following the procedure described by Day and Walker (2015).

\section{Sample decomposition and chemical separation procedures}

The workflow of the sample decomposition and subsequent chemical purification procedures is shown in Figure 1. Approximately $1 \mathrm{~g}$ of powdered sample, a corresponding weighed amount of HSE mixed spike solution, $2.5 \mathrm{ml}$ of $9.5 \mathrm{~mol} \mathrm{l}^{-1} \mathrm{HCl}$ and $7.5 \mathrm{ml}$ of $16 \mathrm{~mol}^{-1} \mathrm{HNO}_{3}$ were transferred into a pre-cleaned CT, which was then flame-sealed. To reduce the vapour pressure of the reagents and to prevent Os loss, the CT was placed in an ethanol-liquid $\mathrm{N}_{2}$ slush kept at $\sim-90^{\circ} \mathrm{C}$ during the whole procedure. The $\mathrm{CT}$ was placed into a stainless-steel jacket, and heated at $240{ }^{\circ} \mathrm{C}$ for $72 \mathrm{~h}$. The stainless-steel jacket was connected to the exhaust post of the laboratory, to prevent leakage of any gas into the oven, which might cause the CT to explode during heating.

This article is protected by copyright. All rights reserved. 
After cooling of the CT, the supernatant solution was transferred into a Savillex PFA vial (25 $\mathrm{ml}$ vol.). Osmium was extracted from the inverse aqua regia by adding $3 \mathrm{ml}$ of $\mathrm{CCl}_{4}$ and shaking the vial (Cohen and Waters 1996, Shen et al. 1996), and then back-extracted from $\mathrm{CCl}_{4}$ into $4 \mathrm{ml}$ of $8.8 \mathrm{~mol} \mathrm{l}^{-1} \mathrm{HBr}$. To achieve high recovery of $\mathrm{Os}$, this process was repeated three times. The $\mathrm{HBr}$ solution $(4 \mathrm{ml})$ was pipetted from $\mathrm{CCl}_{4}$ into a PFA vial $\left(7 \mathrm{ml}\right.$ vol.) and dried at $100{ }^{\circ} \mathrm{C}$. Finally, Os was purified by microdistillation (Birck et al. 1997). The Os-bearing residue was added to $20 \mu \mathrm{l}$ of $\mathrm{H}_{2} \mathrm{SO}_{4}-\mathrm{CrO}_{3}$ solution $\left(8 \% \mathrm{~m} / v\right.$ of $\mathrm{CrO}_{3}$ solution in $\left.12 \mathrm{~mol}^{-1} \mathrm{H}_{2} \mathrm{SO}_{4}\right)$ in the cap of a conical PFA vial (5 $\mathrm{ml}$ vol.). Osmium was vaporised and trapped into $20 \mu \mathrm{l}$ of $8.8 \mathrm{~mol}^{-1} \mathrm{HBr}$ placed in the tip of the conical vial.

The Os-extracted inverse aqua regia solution, with or without an insoluble residue, was used for quantitative treatment of Ru, Pd, Re, Ir and Pt. For the desilicification procedure, the residue in the CT was mixed with the Os-extracted inverse aqua regia solution in a PFA vial ( $25 \mathrm{ml}$ vol.), and then centrifuged. After removing the supernatant solution, the residue was digested in $5 \mathrm{ml}$ of $20 \mathrm{~mol}^{-1} \mathrm{HF}$ (Ishikawa et al. 2014). The HF solution and the supernatant solution were dried at $120^{\circ} \mathrm{C}$, and both fractions were then again dissolved with $6 \mathrm{~mol} \mathrm{l}^{-1} \mathrm{HCl}$ and dried at $120^{\circ} \mathrm{C}$, repeating this procedure three times. Finally, the two solutions were mixed and dried down at $100{ }^{\circ} \mathrm{C}$. For the non-desilicification procedure, only the Os-extracted inverse aqua regia solution was used for mass spectrometric measurement.

Purification of the HSE-bearing solution, to remove matrix elements and interfering elements, was performed in four steps of the ion chromatographic separation procedure, which is summarised in Table 1. The digested sample fraction, dissolved in $10 \mathrm{ml}$ of $0.5 \mathrm{~mol}^{-1} \mathrm{HCl}$ was loaded onto a Bio-Rad polypropylene column (Econo-Pac ${ }^{\circledR}$ Chromatography column with $20 \mathrm{ml}$ bed volume and a 10-ml reservoir), which was packed with Bio-Rad $\mathrm{AG}^{\circledR} 50 \mathrm{~W}-\mathrm{X} 12$ resin (200-400 mesh) (Bio-Rad Laboratories, Hercules, CA, USA). The HSE-rich solution, eluted with $0.5 \mathrm{~mol}^{-1} \mathrm{HCl}$, was evaporated to near dryness and again dissolved in $0.5 \mathrm{~mol}^{-1} \mathrm{HCl}$. The solution was then loaded onto a custom-made low-density polyethylene (LDPE) column ( $0.5 \mathrm{ml}$ bed volume and a 3-ml reservoir), packed with Eichrom-LN resin 
$(100-150 \mu \mathrm{m})($ Eichrom Technologies, Lisle, IL, USA) to separate Y, Zr and Hf. The HSE-rich fraction was eluted with $0.5 \mathrm{~mol} \mathrm{l}^{-1} \mathrm{HCl}$ and evaporated to near dryness, then dissolved in $0.5 \mathrm{~mol}^{-1} \mathrm{HNO}_{3}$. The $\mathrm{HNO}_{3}$ solution was subsequently loaded onto a custom-made LDPE column $(0.1 \mathrm{ml}$ bed volume and a $3-\mathrm{ml}$ reservoir), packed with Bio-Rad Chelex ${ }^{\circledR} 100$ resin (200-400 mesh) to separate the remaining $\mathrm{Zr}$ and $\mathrm{Cd}$ ions from Pd. Using Chelex100 resin, Ru-Re-Ir-Pt-rich and Pd-rich fractions were eluted with $0.5 \mathrm{~mol}^{-1} \mathrm{HNO}_{3}$ and $8 \mathrm{~mol} \mathrm{l}^{-1} \mathrm{HCl}$, respectively. The Ru-Re-Ir-Pt-rich fraction was evaporated to near dryness at $100{ }^{\circ} \mathrm{C}$ and dissolved in $0.5 \mathrm{~mol}^{-1} \mathrm{HNO}_{3}$, which was further purified to remove $\mathrm{Cr}$, using a custom-made LDPE column (0.3 $\mathrm{ml}$ bed volume and a 3-ml reservoir), packed with Bio- $\mathrm{Rad} \mathrm{AG}^{\circledR} 50 \mathrm{~W}-\mathrm{X} 8$ resin (200-400 mesh).

The recovery yields of HSEs and interfering elements after each ion chromatography step were examined using matrix-containing synthetic samples. The matrix powder, ultramafic-mafic in composition $\left(\mathrm{SiO}_{2}=\right.$

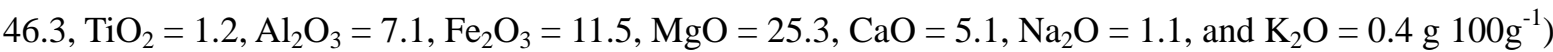
was prepared using chemical reagents (amorphous $\mathrm{SiO}_{2}$, Ti solution in $5 \% \mathrm{HNO}_{3}, \mathrm{Al}$ solution in $5 \% \mathrm{HCl}$, $\mathrm{Fe}_{2} \mathrm{O}_{3}, \mathrm{MgO}, \mathrm{CaCO}_{3}, \mathrm{NaCl}$, and $\mathrm{KNO}_{3}$ ). For the recovery experiments concerning HSEs and interfering elements, a mixture of $\sim 100 \mathrm{ng}$ of $\mathrm{HSEs}$ dissolved in $\mathrm{HCl}$ and a mixture of $\sim 2500 \mu \mathrm{g}$ of $\mathrm{Cr}, \sim 50 \mu \mathrm{g}$ of $\mathrm{Y}$, $\sim 200 \mu \mathrm{g}$ of $\mathrm{Zr}, \sim 500 \mathrm{ng}$ of $\mathrm{Cd}$ and $\sim 5 \mu \mathrm{g}$ of $\mathrm{Hf}$ dissolved in $\mathrm{HCl}$ were mixed with $\sim 1 \mathrm{~g}$ of matrix powder, respectively. Recovery experiments were performed for both desilicification and non-desilicification procedures using the aforementioned two sets (i.e., HSEs and interfering elements) of starting materials. After decomposing the starting materials by inverse aqua regia, each set of samples was added to $5 \mathrm{ml}$ of $20 \mathrm{~mol} \mathrm{l}^{-1} \mathrm{HF}$ and re-dissolved by $6 \mathrm{~mol}^{-1} \mathrm{HCl}$ for the desilicification procedure. For the non-desilicification procedure, each set of samples was only treated with $6 \mathrm{~mol} \mathrm{l}^{-1} \mathrm{HCl}$. Then, each sample was treated using the same procedures as for the RMs. Finally, each sample solution was eluted following the procedures shown in Table 1. The recovery yields of HSEs and interfering elements after each ion chromatography step were determined by isotope dilution and calibration curve methods, respectively. 


\section{Mass spectrometric measurements}

Ruthenium, Pd, Re, Ir and Pt intensities were measured using ICP-MS (ThermoScientific Element XR), and Os isotope ratios were measured as $\mathrm{OsO}_{3}{ }^{-}$by TIMS (ThermoFinnigan TRITON). The ICP-MS measurements were performed using three analytical protocols: $\mathrm{Ru}-\mathrm{Ir}-\mathrm{Pt}$, Re, and Pd analyses. Among these protocols, Ru-Ir-Pt and Pd fractions were measured with dry plasma using a desolvating nebulizer system (CETAC Aridus $\mathrm{II}^{\mathrm{TM}}$ ). For the Re measurements, a wet plasma was used because it is more effective in eliminating the memory effect as described by Fischer-Gödde et al. (2011). The desolvating nebulizer system effectively increases the intensities of target elements with decreasing interference oxide intensities for: ${ }^{53} \mathrm{Cr}^{16} \mathrm{O}_{3}{ }^{+}$on ${ }^{101} \mathrm{Ru}^{+},{ }^{89} \mathrm{Y}^{16} \mathrm{O}^{+}$on ${ }^{105} \mathrm{Pd}^{+},{ }^{90} \mathrm{Zr}^{16} \mathrm{O}^{+}$on ${ }^{106} \mathrm{Pd}^{+},{ }^{177} \mathrm{Hf}^{16} \mathrm{O}^{+}$on ${ }^{193} \mathrm{Ir}^{+},{ }^{178} \mathrm{Hf}^{16} \mathrm{O}^{+}$on ${ }^{194} \mathrm{Pt}^{+}$, and ${ }^{179} \mathrm{Hf}^{16} \mathrm{O}^{+}$on ${ }^{195} \mathrm{Pt}^{+}$. The monitored mass to charge ratio $(\mathrm{m} / \mathrm{z})$ of the analytes and interferences for the Ru-Ir-Pt and Re fractions are m/z $53(\mathrm{Cr}), 99(\mathrm{Ru}), 101(\mathrm{Ru}), 178(\mathrm{Hf}), 185(\mathrm{Re}), 187$ (Re), 188 (Os), 191 (Ir), 193 (Ir), $194(\mathrm{Pt}), 195(\mathrm{Pt})$, and for the Pd fraction are m/z 89 (Y), 90 (Zr), 105 (Pd), $106(\mathrm{Pd}), 112(\mathrm{Cd})$ (Table 2). The $\mathrm{CrO}_{3}{ }^{+} / \mathrm{Cr}^{+}, \mathrm{YO}^{+} / \mathrm{Y}^{+}, \mathrm{ZrO}^{+} / \mathrm{Zr}^{+}$and $\mathrm{HfO}^{+} / \mathrm{Hf}^{+}$ratios were monitored using $200 \mathrm{ng} \mathrm{g}{ }^{-1}$ of $\mathrm{Cr}$ solution, $1 \mathrm{ng} \mathrm{g}^{-1}$ of $\mathrm{Y}$ solution, and $20 \mathrm{ng} \mathrm{g}^{-1}$ of a $\mathrm{Zr}$ and $\mathrm{Hf}$ mixed solution dissolved in $0.5 \mathrm{~mol} \mathrm{l}^{-1} \mathrm{HNO}_{3}$, which was prepared from commercially-available $100-1000 \mu \mathrm{g} \mathrm{g}^{-1}$ standard solutions. When using a desolvating nebulizer system, the production of oxide species was typically $\sim 0.1 \%$ for ${ }^{89} \mathrm{Y}^{16} \mathrm{O}^{+} /{ }^{89} \mathrm{Y}^{+}$and ${ }^{90} \mathrm{Zr}^{16} \mathrm{O}^{+} /{ }^{90} \mathrm{Zr}^{+}, \sim 0.02 \%$ for ${ }^{178} \mathrm{Hf}^{16} \mathrm{O}^{+} /{ }^{178} \mathrm{Hf}^{+}$, and the intensity of ${ }^{53} \mathrm{Cr}^{16} \mathrm{O}_{3}$ was under the detection limit $(<$ $50 \mathrm{cps})$. All measurements were performed in pulse-counting mode and low resolution mode with intensities $<5-6 \times 10^{6} \mathrm{cps}$

For Os isotope measurements, purified Os was loaded on Pt filaments $(0.5 \mathrm{~mm} \times 0.025 \mathrm{~mm}$; purity $99.999 \%$ m/m; H.Cross Company, Moonachie, USA) which had been cleaned previously with 16 mol $\mathrm{l}^{-1} \mathrm{HNO}_{3}$ and baked in air at $3 \mathrm{~A}$ for $2 \mathrm{~min}$. Os dissolved in $8.8 \mathrm{~mol} \mathrm{l}^{-1} \mathrm{HBr}$ was loaded slowly onto the filament and covered with $0.5 \mu \mathrm{l}$ of a $\mathrm{Ba}(\mathrm{OH})_{2}-\mathrm{NaOH}$ activator (Creaser et al. 1991, Völkening et al. 1991) and subsequently heated in air under a heat lamp.

This article is protected by copyright. All rights reserved. 
A gain calibration of the amplifiers was performed at the beginning of every daily measurement session. Oxygen gas was bled into the ion source, maintained at $\sim 3 \times 10^{-5}$ Pa during measurements. Employing a static multi-ion-collection mode using Faraday cups with $10^{11} \Omega$ amplifiers, ${ }^{184} \mathrm{Os}^{16} \mathrm{O}_{3}^{-}\left(10^{12} \Omega\right),{ }^{186} \mathrm{Os}^{16} \mathrm{O}_{3}{ }^{-}$, ${ }^{188} \mathrm{Os}^{16} \mathrm{O}_{3}^{-},{ }^{189} \mathrm{Os}^{16} \mathrm{O}_{3}^{-},{ }^{190} \mathrm{Os}^{16} \mathrm{O}_{3}{ }^{-}$and ${ }^{192} \mathrm{Os}^{16} \mathrm{O}_{3}^{-}$were simultaneously measured. These signals were collected over 10 blocks of 10 cycles with an $8 \mathrm{~s}$ integration time and a $3 \mathrm{~s}$ idle time. When measuring low quantities of Os (<1 ng), a secondary electron multiplier (SEM) in peak-jumping mode was applied. The measurement in peak-jumping mode consisted of five blocks with ten cycles per block, each cycle containing six masses including ${ }^{192} \mathrm{Os}^{16} \mathrm{O}_{3}{ }^{-190}, \mathrm{Os}^{16} \mathrm{O}_{3}{ }^{-},{ }^{189} \mathrm{Os}^{16} \mathrm{O}_{3}{ }^{-},{ }^{188} \mathrm{Os}^{16} \mathrm{O}_{3},{ }^{-187} \mathrm{Os}^{16} \mathrm{O}_{3}{ }^{-}$and ${ }^{186} \mathrm{Os}^{16} \mathrm{O}_{3}^{-}$, with integration times of $2,1,2,4,8$ and $2 \mathrm{~s}$, respectively. The idle time was $3 \mathrm{~s}$ for mass 240 and $0.5 \mathrm{~s}$ for all other masses. Interfering ions $\left({ }^{196} \mathrm{Pt}^{16} \mathrm{O}^{2-},{ }^{198} \mathrm{Pt}^{16} \mathrm{O}^{2-},{ }^{183} \mathrm{~W}^{16} \mathrm{O}^{3-},{ }^{185} \mathrm{Re}^{16} \mathrm{O}^{3-},{ }^{194} \mathrm{Pt}^{16} \mathrm{O}^{3-}\right)$ were measured in peak-jumping mode using a $4 \mathrm{~s}$ integration time for one block of ten cycles, before and after Os measurements, and the time-drifted interference intensities were used for Os data reduction.

Data reduction was performed in the following order on the raw data: correction for interferences, oxygen correction using ${ }^{17} \mathrm{O} /{ }^{16} \mathrm{O}$ and ${ }^{18} \mathrm{O} /{ }^{16} \mathrm{O}$ ratios measured during each analytical session, spike reduction, and instrumental mass fractionation correction using ${ }^{192} \mathrm{Os} /{ }^{188} \mathrm{Os}=3.083$ (Nier 1937) via the exponential law. The ${ }^{17} \mathrm{O} /{ }^{16} \mathrm{O}$ and ${ }^{18} \mathrm{O} /{ }^{16} \mathrm{O}$ ratios were determined in-run measurements on masses $236\left({ }^{188} \mathrm{Os}^{16} \mathrm{O}_{3}{ }^{-}\right), 238$ $\left({ }^{190} \mathrm{Os}^{16} \mathrm{O}_{3}{ }^{-}\right), 239\left({ }^{190} \mathrm{Os}^{16} \mathrm{O}_{2}{ }^{17} \mathrm{O}^{-}\right), 240\left({ }^{192} \mathrm{Os}^{16} \mathrm{O}_{3}{ }^{-}\right), 241\left({ }^{192} \mathrm{Os}^{16} \mathrm{O}_{2}{ }^{17} \mathrm{O}^{-}\right)$and $242\left({ }^{192} \mathrm{Os}^{16} \mathrm{O}^{18} \mathrm{O}^{-}\right)$, similar to those described by Luguet et al. (2008). The ${ }^{186} \mathrm{Os} /{ }^{188} \mathrm{Os},{ }^{187} \mathrm{Os} /{ }^{188} \mathrm{Os}$ and ${ }^{190} \mathrm{Os} /{ }^{188} \mathrm{Os}$ ratios for DROsS (Durham Romil Osmium Standard supplied by IAGeo Limited) yielded $0.11994 \pm 0.00006(0.52 \%$ ), $0.16092 \pm 0.00005(0.31 \%)$ and $1.98381 \pm 0.00010(0.05 \%)$, respectively, using $50 \mathrm{ng}$ of Os measured in static mode $(2 \mathrm{~s}$ and $2 \mathrm{RSD}, \mathrm{n}=20) ; 0.11993 \pm 0.00018(1.5 \%), 0.16091 \pm 0.00012(0.78 \%)$ and 1.98385 $\pm 0.00020(0.10 \%)$, respectively, using $1 \mathrm{ng}$ of Os by static mode ( $2 \mathrm{~s}$ and $2 \mathrm{RSD}, \mathrm{n}=21)$; and $0.11983 \pm$ $0.00097(8.1 \%), 0.16079 \pm 0.00029(1.8 \%$ ) and $1.98451 \pm 0.00377(1.9 \%)$, respectively, using $0.1 \mathrm{ng}$ of Os by a peak-jumping mode ( $2 \mathrm{~s}$ and $2 \mathrm{RSD}, \mathrm{n}=12$ ). These results agreed well with the previously published data for the same material (Luguet et al. 2008, Wittig et al. 2010, Liu and Pearson 2014, Chatterjee and Lassiter 2015, Chu et al. 2015b).

This article is protected by copyright. All rights reserved. 


\section{Results and discussion}

\section{Chemical separation of HSEs}

Step 1, AG50W-X12 resin: Most studies that separate matrix elements from HSEs by cation-exchange chromatography used AG50W-X8 resin (e.g., Meisel et al. 2003a, Shinotsuka and Suzuki 2007, Fischer-Gödde et al. 2011, Li et al. 2014). In this study, we selected an AG50W-X12 resin because it has a greater cation capacity than AG50W-X8. HSE elution curves using $3 \mathrm{ml}$ of AG50W-X8 and -X12 were compared. Although X12 recorded larger tailing for Pt and worse separation of the interfering element $\mathrm{Cr}$ than $\mathrm{X} 8$, it was able to reduce the tailing of Ru and more effectively separate the interfering elements $\mathrm{Zr}$, Hf and Cd (Figure 2). Theoretically, >11 ml (calculation based on ion exchange capacity) of AG50W-X12 resin is necessary to retain all cations in an appropriate bearing solution for $\sim 1 \mathrm{~g}$ of natural silicate rock, ranging in composition from rhyolite to peridotite. In this study, we used $20 \mathrm{ml}$ of resin to avoid the breakthrough of cations (Table 1). The recovery yields of HSEs after the first column were also examined by a calibration curve method using a non-matrix containing synthetic sample (i.e., HSE synthetic solution was prepared from the Precious Metals plasma standard solution). The recoveries of HSEs from both matrix bearing and non-matrix bearing synthetic samples did not change significantly, resulting in $>92 \%$ (Figure 3 ) and $>95 \%$ yields, respectively, while the major cations were reduced to almost negligible amounts. Figure 3 shows that there were no significant differences with regard to the recoveries of interfering elements in the HSE cut between desilicified and non-desilicified matrix-containing synthetic samples: $\sim 6 \%$ for $\mathrm{Cr}$, $<0.2 \%$ for $\mathrm{Y}, \sim 5-8 \%$ for $\mathrm{Zr}, \sim 21-23 \%$ for $\mathrm{Cd}$, and $\sim$

1-6\% for Hf. The cation exchange resin retains $\mathrm{Cr}^{3+}$, mainly forming $\mathrm{Cr}\left(\mathrm{H}_{2} \mathrm{O}\right)_{6}{ }^{3+}$, but it cannot adsorb $\mathrm{Cr}^{6+}$ mostly present in anion complexes such as $\mathrm{Cr}_{2} \mathrm{O}_{7}{ }^{2-}$ or $\mathrm{CrO}_{4}{ }^{2-}$ (Korkish 1989). Therefore, it is important to suppress the formation of $\mathrm{Cr}^{6+}$ in sample solution to retain $\mathrm{Cr}$ in the cation exchange resin. $\mathrm{The} \mathrm{Cr}$ concentration in HSE-bearing solution significantly increased when the sample solution dissolved in $\mathrm{HCl}$ was evaporated at $>110{ }^{\circ} \mathrm{C}$. Thus, the evaporation temperature was set at $100{ }^{\circ} \mathrm{C}$ before sample loading. The majority of $\mathrm{Cr}$ was separated from HSEs through the first column, and further separation of $\mathrm{Cr}$ was achieved at the final purification step, as we will discuss in a later section.

This article is protected by copyright. All rights reserved. 
Step 2, $\mathrm{LN}$ resin: Molecular interferences of $\mathrm{ZrO}^{+}$and $\mathrm{HfO}^{+}$are significant for $\mathrm{Pd}$ and $\mathrm{Ir}-\mathrm{Pt}$, respectively, because of the elevated $\mathrm{Zr} / \mathrm{Pd}, \mathrm{Hf} / \mathrm{Ir}$ and $\mathrm{Hf} / \mathrm{Pt}$ ratios in terrestrial rock samples. To separate $\mathrm{Zr}$ and $\mathrm{Hf}$ from HSEs, $\mathrm{LN}$ resin was used because it can selectively retain $\mathrm{Zr}$ and $\mathrm{Hf}$ chloro-complexes (Münker et al. 2001). Calculations of the distribution coefficient $\left(\mathrm{K}_{\mathrm{d}}\right)$ for the distribution of HSEs, $\mathrm{Zr}$ and Hf between $\mathrm{LN}$ resin and $0.5 \mathrm{~mol} \mathrm{l}^{-1} \mathrm{HCl}$ using batch method (Table 3) yielded extremely high $\mathrm{K}_{\mathrm{d}}$ values for $\mathrm{Zr}$ and $\mathrm{Hf}\left(>10^{6}\right)$ and low values for HSEs ( $<2$ for $\mathrm{Ru}$, Pd, Ir and Pt and 11 for Re). This suggests that a low molarity of $\mathrm{HCl}$ effectively separates $\mathrm{Zr}$, $\mathrm{Hf}$ and $\mathrm{Y}\left(\mathrm{K}_{\mathrm{d}}=\sim 500\right)$ from HSEs. The recoveries of HSEs after the second column were 83-96\% and 90-100\% from desilicified and non-desilicified matrix-containing synthetic samples, respectively. Interfering elements $\mathrm{Zr}$ and $\mathrm{Hf}$ were completely removed by $\mathrm{LN}$ resin for the non-desilicified matrix-containing synthetic sample. However, $\sim 6 \%$ of $\mathrm{Zr}$ and $\sim 3 \%$ of Hf remained in HSE cut for the desilicified matrix-containing synthetic sample (Figure 3). This reveals that fluoro-complexes of $\mathrm{Zr}$ and Hf, which are more stable than chloro-complexes of these elements (Makishima et al. 2009), remained in the solution even after repeated addition of $\mathrm{HCl}$. Because the $\mathrm{K}_{\mathrm{d}}$ values of $\mathrm{Zr}$, Hf and HSEs are nearly identical between $\mathrm{LN}$ resin and $0.5 \mathrm{~mol} \mathrm{l}^{-1} \mathrm{HF}$, it is difficult to separate these elements by the second column (Table 3). Pearson and Woodland (2000) also mentioned the hardness to separate fluoro-complexes of $\mathrm{Zr}$ and $\mathrm{Hf}$ from HSEs using common anion exchange resin AG1-X8. Although using diluted $\mathrm{HF}$ to remove $\mathrm{Zr}$ and $\mathrm{Hf}$ as much as possible, several amounts of these stable anionic fluoro-complexes were still strongly retained with HSEs in AG1-X8 resin, thus leading to severe oxide interferences especially on Pd in some cases (e.g., low Pd concentrations in Zr-rich terrestrial rocks) (Table 2). On the other hand, the first and second columns effectively separated Y from the HSE cut for the desilicified matrix-containing synthetic sample $(\sim 0.2 \%$ and $<0.01 \%$ after first and second columns, respectively), because of the higher $\mathrm{K}_{\mathrm{d}}$ for $\mathrm{Y}$ between $\mathrm{LN}$ resin and $0.5 \mathrm{~mol} \mathrm{l}^{-1} \mathrm{HF}$ than for HSEs (Table 3 ). Nearly all $\mathrm{Cr}$ and $\mathrm{Cd}$ were eluted in the HSE cut for both desilicified and non-desilicified matrix-containing synthetic samples during the second column (Figure 3). 
Step 3, Chelex 100 resin: Chelex 100 resin is an organic ion exchanger containing weakly

acidic iminodiacetic functional groups with strong chelating properties, and forms chelate complexes with numerous metal cations. The actual form of the functional group when acting as a cation exchanger or anion exchanger depends on the $\mathrm{pH}$ of the medium. In this study, Chelex 100 resin was conditioned in an acidic medium. The $\mathrm{K}_{\mathrm{d}}$ values of the target elements with various reagents are shown in Table 3 . The elution profiles of LN resin and Chelex 100 resin using $\sim 1 \mathrm{~g}$ of desilicified TDB-1 are shown in Figure $4 a-b$. The elution profiles of $\mathrm{Hf}$ and $\mathrm{Y}$ are not shown in Figure $4 \mathrm{a}-\mathrm{b}$, because the quantities of $\mathrm{Hf}$ and $\mathrm{Y}$ in the loading solution were reduced to almost negligible levels $(<100 \mathrm{pg})$ in the HSE cut after the second column (Figure 4a). The behaviour of $\mathrm{Hf}$ and $\mathrm{Y}$ is similar to that of $\mathrm{Zr}$, as suggested by the $\mathrm{K}_{\mathrm{d}}$ values of these elements between Chelex 100 resin and $0.5 \mathrm{~mol}^{-1} \mathrm{HNO}_{3}$ and $\mathrm{HF}$ (Table 3). Figure $4 \mathrm{~b}$ shows that interfering elements $\mathrm{Zr}$ and Cd were eluted with Ru-Re-Ir-Pt cut by $0.5 \mathrm{~mol} 1^{-1} \mathrm{HNO}_{3}$, whereas Pd was retained in Chelex 100 resin, which was collected by $8 \mathrm{~mol}^{-1} \mathrm{HCl}$. Thus, the third column could effectively remove the $\mathrm{Zr}$ fluoro-complex and $\mathrm{Cd}$ from Pd. Figure 3 indicates that nearly $100 \%$ of $\mathrm{Ru}, \mathrm{Re}$, Ir and Pt were eluted for the non-desilicified matrix-containing synthetic sample through the third column. However, recoveries of Ru, Re, Ir and Pt for the desilicified matrix-containing synthetic sample were $63-80 \%$. This might be attributed to the presence of fluoro-complexes of HSEs in the loading solution, because $\mathrm{K}_{\mathrm{d}}$ values of HSEs between Chelex 100 resin and $0.5 \mathrm{~mol}^{-1} \mathrm{HF}$ are higher than those for $0.5 \mathrm{~mol}$ $\mathrm{I}^{-1} \mathrm{HNO}_{3}$ (Table 3). The recoveries of Pd for both desilicified and non-desilicified matrix-containing synthetic samples reveal that $\sim 20 \%$ of the loaded Pd were retained in the third column, which could occur due to a strong affinity of Pd in anionic form to Chelex 100 resin.

Our results indicate that it is better to minimise the formation of fluoro-complexes prior to the use of the second and third columns, in order to enhance recoveries of HSEs and remove Hf. Figure 3 shows that recovery of $\mathrm{Hf}$ in the Ru-Re-Ir-Pt cut after the third column for the desilicified matrix-containing synthetic sample was $\sim 3 \%$ while that of the desilicified TDB-1 was almost negligible. The difference of recovery between matrix-containing synthetic sample and RM could be caused by the desilicification procedure. For 
TDB-1, desilicification was only performed for the residue after inverse aqua regia decomposition, whilst it was performed for both the supernatant solution and residue for matrix-containing synthetic sample. We also found that the recovery of $\mathrm{Hf}$ in the Ru-Re-Ir-Pt cut increased when desilicification was performed for both solution and residue for TDB-1, following inverse aqua regia decomposition. Therefore, HF-desilicification was only applied for the sample residue for geological RMs.

[Insert Figure 4a-b]

Step 4, AG50W-X8 resin: It was found that $\sim 6 \%$ of Cr still remained in both desilicified and non-desilicified matrix- containing synthetic samples after the third column (Figure 3). Ru concentrations in terrestrial rock samples are much lower than $\mathrm{Cr}$ concentrations (typically $\mathrm{Cr} / \mathrm{Ru}>400,000$ for basalt and peridotite) and the $\mathrm{Cr} / \mathrm{Ru}$ ratio might possibly increase during $\mathrm{HF}$ desilicification, as $\mathrm{Cr}$ is hosted in silicates or oxide minerals in rocks. Therefore, it would be advisable to further reduce $\mathrm{Cr}$ concentration, because $\mathrm{Cr}$ multi-oxide probably interferes with $\mathrm{Ru}$ in terrestrial rock samples, when no further purification is conducted. Figure 5 shows the elution profiles of HSEs and the interfering element $\mathrm{Cr}$ using $0.3 \mathrm{ml}$ of AG50W-X8 resin. In this study, 60-85\% of Ru, Re, Ir and Pt were collected, and > 99\% of Cr was removed for both desilicified and non-desilicified matrix-containing synthetic samples after the final column (Figure 3), which was modified from the method in Yamakawa et al. (2009).

\section{Recovery yields of HSEs, interfering elements, and blanks}

The recovery yields of HSEs from RM UB-N determined by a calibration curve method, both with and without desilicification, were $~ 60-80 \%$ for $\mathrm{Ru}, \mathrm{Re}$, Ir and Pt and 80-90\% for Pd, which is almost consistent with the results determined by matrix-containing synthetic samples (Figure 3). Several studies previously reported the recoveries of HSEs from geological RMs. Using an anion exchange resin, variable yields ( 30-90\%) of HSEs from mafic and ultramafic RMs were reported by Pearson and Woodland (2000) and Chu et al. (2015a). Using a cation exchange resin, Shinotsuka and Suzuki (2007) showed $~ 70-90 \%$ of 
HSEs for TDB-1 and JP-1. Therefore, the recovery yields achieved in this study were comparable to or better than those reported in the previous studies.

Table 4 shows the ratios of interference intensities relative to the measured intensities of HSE isotope masses during ICP-MS measurement for RMs. The ratios were negligible, as follows: $<1$ parts per million (ppm) for ${ }^{53} \mathrm{Cr}^{16} \mathrm{O}_{3}{ }^{+}$on $m / z 101(\mathrm{Ru})$ and for ${ }^{89} \mathrm{Y}^{16} \mathrm{O}^{+}$on $\mathrm{m} / \mathrm{z} 105(\mathrm{Pd}),<2$ ppm for ${ }^{178} \mathrm{Hf}^{16} \mathrm{O}^{+}$on $\mathrm{m} / \mathrm{z} 194$ and for ${ }^{179} \mathrm{Hf}^{16} \mathrm{O}^{+}$on $m / z 195(\mathrm{Pt})$, and $<26 \pm 20$ ppm for ${ }^{177} \mathrm{Hf}^{16} \mathrm{O}^{+}$on $m / z 193$ (Ir). The sum of ${ }^{106} \mathrm{Cd}^{+}$and ${ }^{90} \mathrm{Zr}^{16} \mathrm{O}^{+}$ exceeded $100 \mathrm{ppm}$ (23-249 ppm) for $\mathrm{m} / z 106$ (Pd), which despite no interference correction, did not affect the result. Therefore, it is concluded that no interference correction is necessary for $\mathrm{Ru}, \mathrm{Pd}, \mathrm{Re}, \mathrm{Ir}$ and $\mathrm{Pt}$ measurements in our analytical method. Because this method can effectively purify Pd with high recovery ( 80-90\%), it has great potential for application to precise Pd isotope analysis.

Total procedural blanks of HSEs ( $\mathrm{n}>10$ ) were $0.9-2.5 \mathrm{pg}$ for Ru, 8.8-25 pg for Pd, 0.01-0.5 pg for Re, 0.05-0.4 pg for Ir, $1.2-18 \mathrm{pg}$ for Pt and 0.9-3.9 pg for Os. Figure 6 shows the comparison of the total procedural blanks in this study with those previously published. The mean values of the Re, Ir and Pt blanks tended to be somewhat lower than those obtained by both CT and high pressure asher (HPA) methods. The main source of Pd in the blank from this study could have come from Chelex 100 resin. This is similar behaviour to that reported in the studies that used an anion exchange resin such as AG1X-8, which contains considerable amounts of Pd (e.g., Pearson and Woodland 2000). Therefore, minimising the contamination of resin blanks using sufficient cleaning procedures is important to keep consistent blank levels (e.g., Becker $e t$ al. 2006, Ishikawa et al. 2014). In this study, the proportions of HSEs in blanks were $0.8-3.5 \%$ for Os and < $1 \%$ for other HSEs for TDB- $1 ; 0.8-2 \%$ for Pd, $0.02-1.3 \%$ for Re and $<1 \%$ for other HSEs for JP- 1 ; and $<1 \%$ for all HSEs for UB-N, MUH-1 and OKUM. Although the proportions of blanks were low, all mass fractions and isotopic compositions were blank-corrected based on the measurement of blanks that were undertaken along with the measurement of the samples.

This article is protected by copyright. All rights reserved. 


\section{HSE mass fractions and Os isotope ratios of reference materials}

The HSE mass fractions and Os isotope ratios of RMs UB-N, JP-1, MUH-1, OKUM and TDB-1 were determined by our analytical method (Table 5 and 6). The primitive upper mantle (PUM)-normalised HSE patterns for these RMs are shown in Figure 8.

UB-N: This reference material a serpentinised fertile lherzolite, is recognised as a relatively homogeneous ultramafic RM for HSE analysis (Meisel and Moser 2004b), and has been determined by many laboratories. All HSE mass fractions determined in our study showed no considerable differences between desilicification and non-desilicification procedures, within a $1 s$ intermediate precision (Table 5 and Figure 8). The Ru, Pd and Ir mean mass fractions were in good agreement with the range of the published data (Figure 7a). The deviations of their mean mass fractions from the published data were $<10 \%$. The Re and Pt mean mass fractions were relatively more variable (the discrepancy for Re and Pt was >15\%) between laboratories, especially for those showing $>100 \%$ higher intermediate precision values than those in our study, such as $\operatorname{Re}\left(0.210 \pm 0.018 \mathrm{ng} \mathrm{g}^{-1}, 1 s\right.$ and $\left.n=9\right)$ in CT data (Ishikawa et al. 2014) and $(0.201 \pm$ $0.012 \mathrm{ng} \mathrm{g}^{-1}, 1 s$ and $\left.n=8\right)$ in HPA data (Fischer-Gödde et al. 2011), and Pt ( $8.07 \pm 1.17 \mathrm{ng} \mathrm{g}^{-1}, 1 s$ and $\left.n=6\right)$ in CT data (Luguet et al. 2007) (Figure 7a). The high variances of the Re and Pt measurement results may be due to other artificial effects other than lab bias. It should be noted that UB-N is distributed only in course grained batches, and powders are presumably further pulverised among independent laboratories. It was observed that $\mathrm{Cr}$ concentrations vary systematically from batch to batch, possibly causing the differences in HSE concentrations (Meisel and Horan 2016). The Os mean mass fraction (Note that Os mass fraction and ${ }^{187} \mathrm{Os} /{ }^{188} \mathrm{Os}$ ratio data were collected prior to desilicification and thus no desilicified data are presented in Figure $7 \mathrm{a}-\mathrm{c}$ ) was $<15 \%$ lower than the published mean values. The mean ${ }^{187} \mathrm{Os} /{ }^{188} \mathrm{Os}$ ratio fell within the range of the previously reported data (Figure 7a). The reproducibility of ${ }^{187} \mathrm{Os} /{ }^{188} \mathrm{Os}$ ratios $(0.48 \%$ RSD) was comparable to that of Ishikawa et al. (2014), but slightly worse than other previous studies. The Ru, Ir and Os (5.0-13.6\% RSD) were more heterogonous than Pt, Pd and Re (1.8-5.2\% RSD) in UB-N (Table 5), which may be due to the nugget effect at the $\sim 1 \mathrm{~g}$ test portion size used in this study. On the other hand, 
$\mathrm{Ru}$, Ir and Os may also reside in alloys or laurite ( $\mathrm{Ru}, \mathrm{Os}, \mathrm{Ir}) \mathrm{S}_{2}$, which are difficult to digest in both aqua regia and HF (Meisel et al. 2003a, b).

JP-1: This is a highly depleted harzburgite, which has been used as an ultramafic RM for HSE analysis in a very limited number of studies (e.g., Meisel and Moser 2004b, Ishikawa et al. 2014). Our results did not display systematic differences between the data for the desilicified and non-desilicified samples, within a $1 s$ intermediate precision (Table 5 and Figure 8). The Pd, Pt, and Os mean mass fractions were in good agreement with the range of the previously reported data (Figure 7b). The desilicified mean mass fraction of Ir also fell within the range of data reported in the literature, but the non-desilicified value did not. Both desilicified and non-desilicified mean mass fractions of Ru were lower than the literature values. The Re mean mass fractions with and without desilicification were consistently $\sim 20 \%$ higher compared with the published data, except for that reported by Meisel and Moser (2004b), which was one order of magnitude higher and with a large intermediate precision $\left(0.29 \pm 0.36 \mathrm{ng} \mathrm{g}^{-1}, 1 s\right.$ and $\left.n=9\right)$ (Figure 7b). The reason for the significant variance of Re values is uncertain. It may reflect the nugget effect. The mean ${ }^{187} \mathrm{Os} /{ }^{188} \mathrm{Os}$ ratio was only $\sim 0.25 \%$ lower than that reported by Ishikawa et al. (2014). Our Pd and Re data (6.8-12\% RSD) were more reproducible than Ru, Ir, Os and Pt data (15-27\% RSD) (Table 5). The large variations in $\mathrm{Ru}$, Ir, Os and Pt data may result from the retention of these elements by the refractory laurite and Pt-rich alloy phases distributed in JP-1. The inclusion of a desilicification step for UB-N and JP-1 did not yield any major differences when compared with non-desilicified data, as demonstrated by our results. A similar finding was reported by Meisel et al. (2003b) and Ishikawa et al. (2014).

MUH-1: The HSE mass fractions of ultramafic RM MUH-1 (a depleted harzburgite) showed no significant differences between those involving desilicification and non-desilicification procedures (Figure 8). Thus, desilicification is not necessary for HSE extractions from MUH-1. The Re mean mass fraction for desilicified samples was $<8 \%$ higher than that for non-desilicified samples within a $1 s$ intermediate precision (Table 5), the reason for which remains obscure. The minor bias was not expected to be the effect 
of desilicification, as some measured quantity values for non-desilicified samples overlapped with the range of the desilicified values.

OKUM: The ultramafic RM OKUM (a komatiite) displayed systematically higher mass fractions of Ru, Ir and Pt in desilicified samples than those in non-desilicified samples, while the mass fractions of Pd and Re were identical among these samples (Table 6 and Figure 8). Moreover, the desilicified mean mass fractions of $\mathrm{Ru}$, Ir, and $\mathrm{Pt}$ were higher than non-desilicified values by 11\%, 24\%, 13\%, respectively. The Pd and Re mean mass fractions with and without desilicification, were in good agreement with the range of non-desilicified HPA data reported by Savard et al. (2010) ( $\mathrm{Pd}=12.20 \pm 6.0 \% \mathrm{RSD} ; \mathrm{Re}=0.566 \pm 6.3 \%$ RSD) and Wang and Becker (2014) $(\mathrm{Pd}=11.8 \pm 4 \% \mathrm{RSD} ; \mathrm{Re}=0.4 \pm 21 \% \mathrm{RSD})$. However, the desilicified mean mass fractions of Ru $(4.39 \pm 1.2 \% \mathrm{RSD})$, Ir $(0.951 \pm 9.3 \% \mathrm{RSD})$ and $\mathrm{Pt}(11.5 \pm 1.7 \% \mathrm{RSD})$ seemed more consistent with HPA data from both Savard et al. $(2010)(\mathrm{Ru}=4.15 \pm 2.0 \% \mathrm{RSD} ; \mathrm{Ir}=0.943 \pm 3.9 \%$ $\mathrm{RSD} ; \mathrm{Pt}=11.44 \pm 1.9 \% \mathrm{RSD})$ and Wang and Becker $(2014)(\mathrm{Ru}=4.44 \pm 2 \% \mathrm{RSD} ; \mathrm{Ir}=0.897 \pm 8 \% \mathrm{RSD})$ (Table 6). This could be explained by incomplete digestion of OKUM by the CT method used in this study (i.e., $\mathrm{Ru}, \mathrm{Ir}$ and Pt may be released more completely from the sample matrix at elevated temperatures with prolonged heating, even without HF treatment). Nevertheless, desilicification is somewhat useful to liberate $\mathrm{Ru}$, Ir and Pt from sample residues following CT decomposition. Furthermore, it should be noted that Pt (46\% RSD) and Os (97\% RSD) in OKUM reported by Wang and Becker (2014) were particularly heterogeneous (at $0.5-1 \mathrm{~g}$ test portion size), which demonstrates that Pt and Os concentrations may be significantly influenced by the nugget effect. The variance of Os data was also observed in our study, but they were more reproducible (15\% RSD). As shown in Figure 8, it is evident that the homogeneity of HSEs in harzburgites JP-1 and MUH-1 are generally much worse than those in lherzolite UB-N and komatiite OKUM, due to the nugget effect. Most of the HSEs in harzburgite are hosted in difficult to digest minerals such as laurite and alloys, which increases sample heterogeneity, whereas the dominant HSE-bearing phases in lherzolite and komatiite are base metal sulfides (Meisel et al. 2013).

This article is protected by copyright. All rights reserved. 
TDB-1: This mafic RM, a diabase, is a widely used for HSE measurements (e.g., Meisel and Moser 2004a, b, Ishikawa et al. 2014). Our results demonstrate that the mean mass fractions of $\mathrm{Ru}$ and $\mathrm{Re}$ from the desilicification procedure were higher than those from the non-desilicification procedure, by $\sim 30 \%$ and $\sim 10 \%$, respectively, while the mean mass fractions of Pd, Ir and Pt were identical between these two procedures, within a $1 s$ intermediate precision (Table 6 and Figure 8). The problems of incomplete recovery of HSEs in TDB-1 during acid digestion have been pointed out elsewhere (e.g., Dale et al. 2009, Meisel et al. 2009). Dale et al. (2012b) showed the efficient extraction of Ru and Re from TDB-1 using HF-desilicification following HPA decomposition. Ishikawa et al. (2014) examined the effectiveness of different digestion methods and conditions on HSE extractions in TDB-1. Both Ishikawa et al. (2014) and Meisel and Horan (2016) concluded that Re in TDB-1 could be completely extracted from the sample matrix at elevated temperatures over prolonged heating in aqua regia, even without additional desilicification. By contrast, the full extraction of $\mathrm{Ru}$ was dependent on $\mathrm{HF}$ treatment. Therefore, the result of the higher desilicified $\mathrm{Ru}$ and $\mathrm{Re}$ values, relative to non-desilicified values obtained in this study, also supports the previous theory that desilicification is useful to enhance Ru and Re extractions from TDB-1 (e.g., Meisel et al. 2009, Dale et al. 2009, 2012b, Ishikawa et al. 2014, Ackerman et al. 2016, Jonášová et al. 2016). Instead, the identical Pd, Ir and Pt values with and without desilicification imply that they were completely extracted from the sample matrix during non-desilicification procedure. The Os mean mass fraction was consistent with the reported data of both CT and HPA methods, except for those of Ishikawa et al. (2014), Qi and Zhou (2008) and Savard et al. (2010). The large variance in Os data observed between laboratories could result from the nugget effect. The ${ }^{187} \mathrm{Os} /{ }^{188} \mathrm{Os}$ ratios agreed well with the previously reported CT and HPA data, within a $1 s$ intermediate precision (Figure $7 \mathrm{c}$ ).

\section{Conclusions}

An effective analytical method was developed for the determination of HSE mass fractions and Os isotopic compositions in geological samples, by high-resolution ICP-MS and N-TIMS, respectively. The procedure enabled the use of the same aliquot for both ICP-MS and N-TIMS measurements and utilised an isotope

This article is protected by copyright. All rights reserved. 
dilution method. This study presents two new methodologies for the ion-exchange separation of Ru, Pd, Re, Ir and Pt: (1) The cation exchange resin AG50W-X12 can more effectively separate HSEs, in particular Ru, from matrix elements than the -X8, generally used in previous studies, (2) When the HF-desilicification was performed following sample decomposition, trace amounts of $\mathrm{Zr}$, forming stable fluoro-complex, cannot be removed by $\mathrm{LN}$ resin. Chelex 100 resin, however, can effectively separate $\mathrm{Pd}$ from the $\mathrm{Zr}$ fluoro-complex, because the $\mathrm{K}_{\mathrm{d}}$ of $\mathrm{Pd}$ is $\sim 1000-3000$ times higher than that for $\mathrm{Zr}$ in both diluted $\mathrm{HF}$ and $\mathrm{HNO}_{3}$. Furthermore, the Cr multi-oxide interference in Ru measurements, rarely discussed in previous studies, was critically evaluated. In this method, with careful purification and utilisation of a desolvating nebulizer system, the ratios of the interference intensities relative to the measured intensities of HSE isotope masses: $\mathrm{CrO}_{3}^{+} / \mathrm{Ru}^{+}$ (101), $\mathrm{YO}^{+} / \mathrm{Pd}^{+}(105), \mathrm{Cd}^{+} / \mathrm{Pd}^{+}(106), \mathrm{ZrO}^{+} / \mathrm{Pd}^{+}(106), \mathrm{HfO}^{+} / \mathrm{Ir}^{+}(193)$ and $\mathrm{HfO}^{+} / \mathrm{Pt}^{+}(194,195)$, were reduced by less than a few hundred parts per million. Thus, no interference correction is required for the measurements of Ru, Pd, Re, Ir and Pt for both desilicified and non-desilicified geological samples. The contributions of the total procedural blank of HSEs in RMs were $<1 \%$ and did not significantly affect the measurement results.

Our data for HSE mass fractions and Os isotopic compositions of RMs UB-N, JP-1 and TDB-1, commonly used between laboratories, were in good agreement with or comparable to the literature data, demonstrating the validation of our analytical method. Furthermore, the effectiveness of HF-desilicification on the Ru, Pd, Re, Ir and Pt extractions from the sample matrix was evaluated for UB-N, JP-1, TDB-1, and two new CRMs MUH-1 and OKUM. Our results indicate that desilicification, followed by CT decomposition using inverse aqua regia, more effectively extracted Ru and Re for the mafic RM TDB-1, but not for the ultramafic RMs UB-N and JP-1, the results of which are consistent with previous studies. The ultramafic RM MUH-1, similar to UB-N and JP-1, does not require HF treatment. The ultramafic RM OKUM gave a different result. In this study, the systematically higher Ru, Ir and Pt values for the desilicified samples, compared with those of non-desilicified samples, demonstrate that desilicification improved the liberation of Ru, Ir and Pt from OKUM. Knowing that this study used a $\sim 1 \mathrm{~g}$ test portion size, among four ultramafic RMs, the homogeneity 
of HSEs in harzburgites JP-1 and MUH-1 are generally worse than those in lherzolite UB-N and komatiite OKUM

\section{Acknowledgements}

T.C. Meisel is warmly thanked for his valuable discussions about the reference materials and the manuscript. We also thank A. Makishima, K. Kobayashi, T. Kunihiro, H. Kitagawa, T. Ota, and K. Tait for discussions, and K. Tanaka for assistance in the laboratory. We are grateful to G. E. Bebout, C. Potiszil and M.-L. Avramescu for improving the initial manuscript. This study was funded by Ministry of Education, Culture, Sports, Science and Technology (MEXT, Japan) through the program "Establishment of the international research-education centre for pioneering planetary material science".

\section{References}

Ackerman L., Bizimi M., Haluzová E., Sláma J., Svojtka M., Hirajima T. and Erban V. (2016)

$\mathrm{Re}-\mathrm{Os}$ and $\mathrm{Lu}-\mathrm{Hf}$ isotopic constraints on the formation and age of mantle pyroxenites from the Bohemian Massif. Lithos, 256, 197-210.

Barnes S.J. and Ripley E.M. (2016)

Highly siderophile and strongly chalcophile elements in magmatic ore deposits. Reviews in Mineralogy and Geochemistry, 81, 725-774.

Becker H., Horan M.F., Walker R.J., Gao S., Lorand J.P. and Rudnick R.L. (2006)

Highly siderophile element composition of the Earth's primitive upper mantle: Constraints from new data on peridotite massifs and xenoliths. Geochimica et Cosmochimica Acta, 70, 4528-4550.

Becker H., Morgan J.W., Walker R.J., MacPherson G.J. and Grossman J.N. (2001)

This article is protected by copyright. All rights reserved. 
Rhenium osmium systematics of calcium-aluminium-rich inclusions in carbonaceous chondrites.

Geochimica et Cosmochimica Acta, 65, 3379-3390.

Becker H. and Dale C.W. (2016)

Re-Pt-Os isotopic and highly siderophile element behavior in oceanic and continental mantle tectonites.

Reviews in Mineralogy and Geochemistry, 81, 369-440.

Birck J.L., Barman M.R. and Capmas F. (1997)

Re-Os isotopic measurements at the femtomole level in natural samples. Geostandards Newsletter: The Journal of Geostandards and Geoanalysis, 21, 19-27.

Brandon A.D., Norman M.D., Walker R.J. and Morgan J.W. (1999)

${ }^{186} \mathrm{Os}-{ }^{187}$ Os systematics of Hawaiian picrites. Earth and Planetary Science Letters, 174, 25-42.

Brandon A.D. and Walker R.J. (2005)

The debate over core-mantle interaction. Earth and Planetary Science Letters, 232, 211-225.

Brandon A.D., Walker R.J. and Puchtel I.S. (2006)

Platinum-osmium isotope evolution of the Earth's mantle: Constraints from chondrites and Os-rich alloys.

Geochimica et Cosmochimica Acta, 70, 2093-2103.

Burnham O.M., Meisel T., and Kriete C. (2010)

OKUM and MUH-1: Two new IAG-certified ultramafic rock reference materials. Geochimica et Cosmochimica Acta, 74, A129.

Chatterjee R. and Lassiter J.C. (2015)

This article is protected by copyright. All rights reserved. 
High precision Os isotopic measurement using N-TIMS: Quantification of various sources of error in ${ }^{186} \mathrm{Os} /{ }^{188}$ Os measurements. Chemical Geology, 396, 112-123.

Chu Z., Yan Y., Chen Z., Guo J., Yang Y., Li C. and Zhang Y. (2015a)

A comprehensive method for precise determination of Re, Os, Ir, Ru, Pt, Pd concentrations and Os isotopic compositions in geological samples. Geostandards and Geoanalytical Research, 39, 151-169.

Chu Z.Y., Li C.F., Chen Z., Xu J.J., Di Y.K. and Guo J.H. (2015b)

High-precision measurement of ${ }^{186} \mathrm{Os} /{ }^{188} \mathrm{Os}$ and ${ }^{187} \mathrm{Os} /{ }^{188} \mathrm{Os}$ : Isobaric oxide corrections with in-run measured oxygen isotope ratios. Analytical Chemistry, 87, 8765-8771.

Cohen A.S. and Waters F.G. (1996)

Separation of osmium from geological materials by solvent extraction for analysis by thermal ionisation mass spectrometry. Analytica Chimica Acta, 332, 269-275.

Creaser R.A., Papanastassiou D.A. and Wasserburg G.J. (1991)

Negative thermal ion mass spectrometry of osmium, rhenium and iridium. Geochimica et Cosmochimica Acta, 55, 397-401.

Dale C.W., Burton K.W., Pearson D.G., Gannoun A., Alard O., Argles T.W. and Parkinson I. J. (2009)

Highly siderophile element behaviour accompanying subduction of oceanic crust: Whole rock and mineral-scale insights from a high-pressure terrain. Geochimica et Cosmochimica Acta, 73, 1394-1416.

Dale C.W., Burton K.W., Greenwood R.C., Gannoun A., Wade J., Wood B.J. and Pearson D.G. (2012a)

This article is protected by copyright. All rights reserved. 
Late accretion on the earliest planetesimals revealed by the highly siderophile elements. Science, $\mathbf{3 3 6}$, $72-75$.

Dale C.W., Macpherson C.G., Pearson D.G., Hammond S.J. and Arculus R.J. (2012b)

Inter-element fractionation of highly siderophile elements in the Tonga Arc due to flux melting of a depleted source. Geochimica et Cosmochimica Acta, 89, 202-225.

Day J.M.D. and Walker R.J. (2015)

Highly siderophile element depletion in the Moon. Earth and Planetary Science Letters, 423, 114-124.

Day J.M.D., Brandon A.D. and Walker R.J. (2016a)

Highly siderophile elements in Earth, Mars, the Moon, and asteroids. Reviews in Mineralogy and Geochemistry, 81, 161-238.

Day J.M.D., Waters C.L., Schaefer B.F., Walker R.J. and Turner S. (2016b)

Use of hydrofluoric acid desilicification in the determination of highly siderophile element abundances and Re-Pt-Os isotope systematics in mafic-ultramafic rocks. Geostandards and Geoanalytical Research, 40, $49-65$.

Ely J.C., Neal C.R., O'Neill J.A. and Jain J.C. (1999)

Quantifying the platinum group elements (PGEs) and gold in geological samples using cation exchange pretreatment and ultrasonic nebulization inductively coupled plasma-mass spectrometry (USN-ICP-MS). Chemical Geology, 157, 219-234.

Fischer-Gödde M., Becker H. and Wombacher F. (2011)

This article is protected by copyright. All rights reserved. 
Rhodium, gold and other highly siderophile elements in orogenic peridotites and peridotite xenoliths.

Chemical Geology, 280, 365-383.

Gannoun A., Burton K.W., Day J.M.D., Harvey J., Schiano P. and Parkinson I. (2016)

Highly siderophile element and Os isotope systematics of volcanic rocks at divergent and convergent plate boundaries and in intraplate settings. Reviews in Mineralogy and Geochemistry, 81, 651-724.

Horan M.F., Walker R.J., Morgan J.W., Grossman J.N. and Rubin A.E. (2003)

Highly siderophile elements in chondrites. Chemical Geology, 196, 27-42.

Ishikawa A., Senda R., Suzuki K., Dale C. W. and Meisel T. (2014)

Re-evaluating digestion methods for highly siderophile element and ${ }^{187}$ Os isotope analysis: Evidence from geological reference materials. Chemical Geology, 384, 27-46.

Jarvis I., Totland M.M. and Jarvis K.E. (1997a)

Determination of the platinum-group elements in geological materials by ICP-MS using microwave digestion, alkali fusion and cation-exchange chromatography. Chemical Geology, 143, 27-42.

\section{Jarvis I., Totland M.M. and Jarvis K.E. (1997b)}

Assessment of Dowex 1-X8-based anion-exchange procedures for the separation and determination of ruthenium, rhodium, palladium, iridium, platinum and gold in geological samples by inductively coupled plasma mass spectrometry. Analyst, 122, 19-26.

Jonášová ̌̌., Ackerman L., Žák K., Skála R., Ďurišová J., Deutsch A. and Magna T. (2016)

Geochemistry of impact glasses and target rocks from the Zhamanshin Impact Structure, Kazakhstan:

Implications for mixing of target and impactor matter. Geochimica et Cosmochimica Acta, 190, 239-264.

This article is protected by copyright. All rights reserved. 
Kogiso T., Suzuki K., Suzuki T., Shinotsuka K., Uesugi K., Takeuchi A. and Suzuki Y. (2008)

Detecting micrometer-scale platinum-group minerals in mantle peridotite with microbeam synchrotron radiation X-ray fluorescence analysis. Geochemistry, Geophysics, Geosystems, 9, Q03018, doi:10.1029/2007GC001888.

\section{Korkish J. (1989)}

Handbook of ion exchange resins: The application to analytical inorganic analytcial chemistry. CRC Press (Boca Raton, USA), 352pp.

\section{Li J., Jiang X.Y., Xu J.F., Zhong L.F., Wang X.C., Wang G.Q. and Zhao P.P. (2014)}

Determination of platinum-group elements and Re-Os isotopes using ID-ICP-MS and N-TIMS from a single digestion after two-stage column separation. Geostandards and Geoanalytical Research, $\mathbf{3 8 ,}$ $37-50$.

Li J., Zhao P.P., Liu J., Wang X.C., Yang A.Y., Wang G.Q. and Xu J.F. (2015)

Reassessment of hydrofluoric acid desilicification in the Carius tube digestion technique for Re-Os isotopic determination in geological samples. Geostandards and Geoanalytical Research, 39, 17-30.

\section{Liu J. and Pearson D.G. (2014)}

Rapid, precise and accurate Os isotope ratio measurements of nanogram to sub-nanogram amounts using multiple Faraday collectors and amplifiers equipped with $10^{12} \Omega$ resistors by N-TIMS. Chemical Geology, 363, 301-311.

Luguet A., Nowell G.M. and Pearson D.G. (2008)

This article is protected by copyright. All rights reserved. 
${ }^{184} \mathrm{Os} /{ }^{188} \mathrm{Os}$ and ${ }^{186} \mathrm{Os} /{ }^{188} \mathrm{Os}$ measurements by negative thermal ionisation mass spectrometry (N-TIMS):

Effects of interfering element and mass fractionation corrections on data accuracy and precision. Chemical

Geology, 248, 342-362.

Luguet A., Shirey S.B., Lorand J.P., Horan M.F. and Carlson R.W. (2007)

Residual platinum-group minerals from highly depleted harzburgites of the Lherz massif (France) and their role in HSE fractionation of the mantle. Geochimica et Cosmochimica Acta, 71, 3082-3097.

Makishima A. and Nakamura E. (2001)

Determination of total sulfur at microgram per gram levels in geological materials by oxidation of sulfur into sulfate with in situ generation of bromine using isotope dilution high-resolution ICPMS. Analytical chemistry, 73, 2547-2553.

Makishima A., Tanaka R. and Nakamura E. (2009)

Precise elemental and isotopic analyses in silicate samples employing ICP-MS: Application of hydrofluoric acid solution and analytical techniques. Analytical Sciences, 25, 1181-1187.

Meisel T., Burnham M., Kriete C., Bokhari S.N. and Schulz T. (2013)

Osmium isotope and PGE reference materials OKUM and MUH-1. Mineralogical Magazine, 77, 1734.

Meisel T., Dale C., Pearson D. and Sergeev D. (2009)

Complete sample digestions for accurate isotope measurements? The Re-Os isotope system under scrutiny.

Geochimica et Cosmochimica Acta Supplement, 73, 867.

Meisel T. and Horan M.F. (2016)

This article is protected by copyright. All rights reserved. 
Analytical methods for the highly siderophile elements. Reviews in Mineralogy and Geochemistry, 81, 89-106.

Meisel T., Moser J., Fellner N., Wegscheider W. and Schoenberg R. (2001)

Simplified method for the determination of Ru, Pd, Re, Os, Ir and Pt in chromitites and other geological materials by isotope dilution ICP-MS and acid digestion. Analyst, 126, 322-328.

\section{Meisel, T., Fellner, N. and Moser, J. (2003a)}

A simple procedure for the determination of platinum group elements and rhenium $(\mathrm{Ru}, \mathrm{Rh}, \mathrm{Pd}, \mathrm{Re}, \mathrm{Os}, \mathrm{Ir}$ and Pt) using ID-ICP-MS with an inexpensive on-line matrix separation in geological and environmental materials. Journal of Analytical Atomic Spectrometry, 18, 720-726.

Meisel T., Reisberg L., Moser J., Carignan J., Melcher F. and Brügmann G. (2003b)

Re-Os systematics of UB-N, a serpentinised peridotite reference material. Chemical Geology, 201, $161-179$.

\section{Meisel T. and Moser J. (2004a)}

Platinum-group element and rhenium concentrations in low abundance reference materials. Geostandards and Geoanalytical Research, 28, 233-250.

\section{Meisel T. and Moser J. (2004b)}

Reference materials for geochemical PGE analysis: New analytical data for Ru, Rh, Pd, Os, Ir, Pt and Re by isotope dilution ICP-MS in 11 geological reference materials. Chemical Geology, 208, 319-338.

Münker C., Weyer S., Scherer E. and Mezger K. (2001)

This article is protected by copyright. All rights reserved. 
Separation of high field strength elements ( $\mathrm{Nb}, \mathrm{Ta}, \mathrm{Zr}, \mathrm{Hf})$ and Lu from rock samples for MC-IPMS

measurements. Geochemistry, Geophysics, Geosystems, 2, 10.1029/2001GC000183.

Nakamura E., Makishima A., Moriguti T., Kobayashi K., Sakaguchi C., Yokoyama T., Tanaka R.,

Kuritani T. and Takei H. (2003)

Comprehensive geochemical analyses of small amounts $(<100 \mathrm{mg})$ of extraterrestrial samples for the analytical competition related to the sample return mission MUSES-C. ISAS Report SP, 16, 49-101.

Nier A.O. (1937)

The isotopic constitution of osmium. Physical Review, 52, 885.

Pearson D.G. and Woodland S.J. (2000)

Solvent extraction/anion exchange separation and determination of PGEs (Os, Ir, Pt, Pd, Ru) and Re-Os isotopes in geological samples by isotope dilution ICP-MS. Chemical Geology, 165, 87-107.

Puchtel I.S., Walker R.J., James O.B. and Kring D.A. (2008)

Osmium isotope and highly siderophile element systematics of lunar impact melt breccias: Implications for the late accretion history of the Moon and Earth. Geochimica et Cosmochimica Acta, 72, 3022-3042.

\section{Qi L., Zhou M.F. and Wang C.Y. (2004)}

Determination of low concentrations of platinum group elements in geological samples by ID-ICP-MS.

Journal of Analytical Atomic Spectrometry, 19, 1335-1339.

Qi L. and Zhou M.F. (2008)

Platinum-group elemental and Sr-Nd-Os isotopic geochemistry of Permian Emeishan flood basalts in Guizhou Province, SW China. Chemical Geology, 248, 83-103.

This article is protected by copyright. All rights reserved. 
Rehkämper M. and Halliday A.N. (1997)

Development and application of new iondashexchange techniques for the separation of the platinum group and other siderophile elements from geological samples. Talanta, 44, 663-672.

Ren M., Sun Y., Wang C.Y. and Sun S. (2016)

Determination of platinum-group elements in geological samples by isotope dilution-inductively coupled plasma-mass spectrometry combined with sulfide fire assay preconcentration. Geostandards and Geoanalytical Research, 40, 67-83.

Savard D., Barnes S J. and Meisel T. (2010)

Comparison between nickel-sulfur fire assay Te Co-precipitation and isotope dilution with high-pressure asher acid digestion for the determination of platinum-group elements, rhenium and gold. Geostandards and Geoanalytical Research, 34, 281-291.

Shen J.J., Papanastassiou D.A. and Wasserburg G.J. (1996)

Precise Re-Os determinations and systematics of iron meteorites. Geochimica et Cosmochimica Acta, 60, $2887-2900$.

\section{Shinotsuka K. and Suzuki K. (2007)}

Simultaneous determination of platinum group elements and rhenium in rock samples using isotope dilution inductively coupled plasma mass spectrometry after cation exchange separation followed by solvent extraction. Analytica Chimica Acta, 603, 129-139.

\section{Shirey S.B. and Walker R.J. (1995)}

Carius tube digestion for low-blank rhenium-osmium analysis. Analytical Chemistry, 67, 2136-2141.

This article is protected by copyright. All rights reserved. 
Smoliar M.I., Walker R.J. and Morgan J.W. (1996)

Re-Os ages of group IIA, IIIA, IVA, and IVB iron meteorites. Science, 271, 1099-1102.

Völkening J., Walczyk T., and Heumann K.G. (1991)

Osmium isotope ratio determinations by negative thermal ionization mass spectrometry. International Journal of Mass Spectrometry and Ion Processes, 105, 147-159.

Walker R.J., Brandon A.D., Bird J.M., Piccoli P.M., McDonough W.F. and Ash R.D. (2005)

${ }^{187} \mathrm{Os}-{ }^{186}$ Os systematics of Os-Ir-Ru alloy grains from southwestern Oregon. Earth and Planetary Science

Letters, 230, 211-226.

Wang Z. and Becker H. (2014)

Abundances of sulfur, selenium, tellurium, rhenium and platinum-group elements in eighteen reference materials by isotope dilution sector-field ICP-MS and negative TIMS. Geostandards and Geoanalytical

Research, 38, 189-209.

Wittig N., Pearson D.G., Baker J.A., Duggen S. and Hoernle K. (2010)

A major element, PGE and Re-Os isotope study of Middle Atlas (Morocco) peridotite xenoliths: Evidence for coupled introduction of metasomatic sulphides and clinopyroxene. Lithos, 115, 15-26.

Yamakawa A., Yamashita K., Makishima A. and Nakamura E. (2009)

Chemical separation and mass spectrometry of $\mathrm{Cr}, \mathrm{Fe}, \mathrm{Ni}, \mathrm{Zn}$, and $\mathrm{Cu}$ in terrestrial and extraterrestrial materials using thermal ionization mass spectrometry. Analytical Chemistry, 81, 9787-9794.

This article is protected by copyright. All rights reserved. 


\section{Figure captions}

Figure 1. The Workflow diagram for separations and determination of HSE mass fractions and Os isotope ratios developed in this study.

Figure 2. Elution profiles of HSEs and interfering elements (non-matrix containing synthetic solutions) for $3 \mathrm{ml}$ of AG50W-X8 (broken line) and -X12 (solid line). The insert for HSEs shows the tailing of Ru, Pd, Re, Ir and Pt eluting from 6 to $12 \mathrm{ml}$ for both X8 and X12.

Figure 3. Recovery yields of HSEs and interfering elements (Cr, Y, Zr, Cd and Hf) for each column using a matrix-containing synthetic sample (a) without and (b) with desilicification. 1: AG50W-X12 resin, 2: LN resin, 3: Chelex 100 resin, 4: AG50W-X8 resin. For the third column, two fractions were collected, the Ru-Re-Ir-Pt cut, and the other the Pd cut (Figure 4b). The recoveries shown for the third column are: Ru, Re, Ir, Pt, Hf and Cr for the Ru-Re-Ir-Pt cut and Pd, Zr, Y and Cd for the Pd cut.

Figure 4. Elution profiles of HSEs and interfering elements (desilicified RM TDB-1) for (a) the second column LN resin and (b) third column Chelex100 resin: Pd was successfully separated from $\mathrm{Zr}$ and $\mathrm{Cd}$.

Figure 5. Elution profiles of HSEs and the interfering element $\mathrm{Cr}$ (non-matrix containing synthetic solutions: $10 \mathrm{ng}$ of HSEs and $10 \mu \mathrm{g}$ of $\mathrm{Cr}$, respectively) for the fourth column AG50W-X8 resin.

Figure 6. The range of total procedural blanks from this study and previous studies, CT: Carius tube digestion method, HPA: high-pressure asher digestion method.

Figure 7. HSE mass fractions and Os isotope ratios for RMs (a) UB-N, (b) JP-1 and (c) TDB-1. Comparison with previous studies (error bar: $1 s$ ), CT: Carius tube without desilicification, CT-HF: Carius tube with post-Os desilicification, HPA: high-pressure asher without desilicification, HPA-HF:

This article is protected by copyright. All rights reserved. 
high-pressure asher with post-Os desilicification. Os data of CT-HF represent Os data employing a CT from both the current study and previous studies.

Figure 8. PUM-normalised HSE patterns for RMs TDB-1, OKUM, UB-N, MUH-1 and JP-1, respectively with and without desilicification from this study. The grey lines denote HSE patterns of DS. The PUM data are from Becker et al. (2006). DS: HF-desilicification.

This article is protected by copyright. All rights reserved. 
Table 1.

Separation scheme for Ru-Pd-Ir-Re-Pt purification

\section{(1) Separation of Ru-Pd-Ir-Re-Pt from matrix elements}

Econo-Pac chromatography column packed with $20 \mathrm{ml}$ AG50WX12, 200-400 mesh

Column dimension: $15 \mathrm{~mm}$ wide $\times 120 \mathrm{~mm}$ long

Resin cleaning

$150 \mathrm{ml}^{2} \mathrm{~mol} \mathrm{I}^{-1} \mathrm{HCl}$

Conditon

$100 \mathrm{ml}^{0.5} \mathrm{~mol} \mathrm{I}^{-1} \mathrm{HCl}$

Load sample

$6 \mathrm{ml} 0.5 \mathrm{~mol} \mathrm{I}^{-1} \mathrm{HCl}$

Load and collect sample

$4 \mathrm{ml}^{0} .5 \mathrm{~mol} \mathrm{I}^{-1} \mathrm{HCl}$

Collect sample

$8 \mathrm{ml} 0.5 \mathrm{moll}^{-1} \mathrm{HCl}$

\section{(2) Separation of Ru-Pd-Ir-Re-Pt from Y, Zr, Hf}

LDPE column packed with $0.5 \mathrm{ml}$ LN resin, $100-150 \mu \mathrm{m}$

Column dimension: $4 \mathrm{~mm}$ wide $\times 45 \mathrm{~mm}$ long

Resin cleaning

$3 \mathrm{ml} 0.5 \mathrm{~mol} \mathrm{l}^{-1} \mathrm{HF}$

Resin cleaning

$3 \mathrm{ml}$ Mili-Q

Resin cleaning

$6 \mathrm{ml} 6 \mathrm{moll}^{-1} \mathrm{HCl}$

Resin cleaning

$3 \mathrm{ml}$ Mili-Q

Conditon

Load and collect sample

$3 \mathrm{ml} 0.5 \mathrm{~mol} \mathrm{I}^{-1} \mathrm{HCl}$

Collect sample

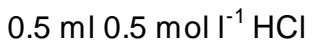

\section{(3) Separation of Pd from Cd and Zr fluoro-complex}

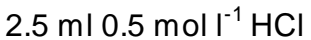

LDPE column packed with $0.1 \mathrm{ml}$ Chelex100, 200-400 mesh, sodium form

Column dimension: $4 \mathrm{~mm}$ wide $\times 10 \mathrm{~mm}$ long

Resin cleaning

Resin cleaning

$9 \mathrm{ml} 9.5 \mathrm{~mol} \mathrm{I}^{-1} \mathrm{HCl}$

Conditon

Load and collect sample

Collect sample (Ru-Re-Ir-Pt fraction)

Collect sample (Pd fraction)

\section{(4) Separation of Ru-Re-Ir-Pt from Cr}

LDPE column packed with $0.3 \mathrm{ml}$ AG50WX8, 200-400 mesh

Column dimension: $4 \mathrm{~mm}$ wide $\times 30 \mathrm{~mm}$ long

Resin cleaning

Resin cleaning

Conditon

Load and collect sample

$3 \mathrm{ml}$ Mili-Q

$3 \mathrm{ml} 0.5 \mathrm{~mol} \mathrm{I}^{-1} \mathrm{HNO}_{3}$

$0.5 \mathrm{ml}^{0} 0.5 \mathrm{~mol} \mathrm{I}^{-1} \mathrm{HNO}_{3}$

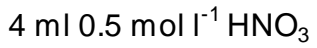

Collect sample

$6 \mathrm{ml} 6 \mathrm{~mol} \mathrm{I}^{-1} \mathrm{HCl}$

$3 \mathrm{ml}$ Mili-Q

$3 \mathrm{ml}^{0} 0.5 \mathrm{~mol} \mathrm{I}^{-1} \mathrm{HNO}_{3}$

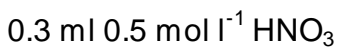

$0.6 \mathrm{ml}^{0} .5 \mathrm{moll}^{-1} \mathrm{HNO}_{3}$

This article is protected by copyright. All rights reserved. 
Table 2.

Isobaric and potential polyatomic interferences for HSE measurements by ICP-MS

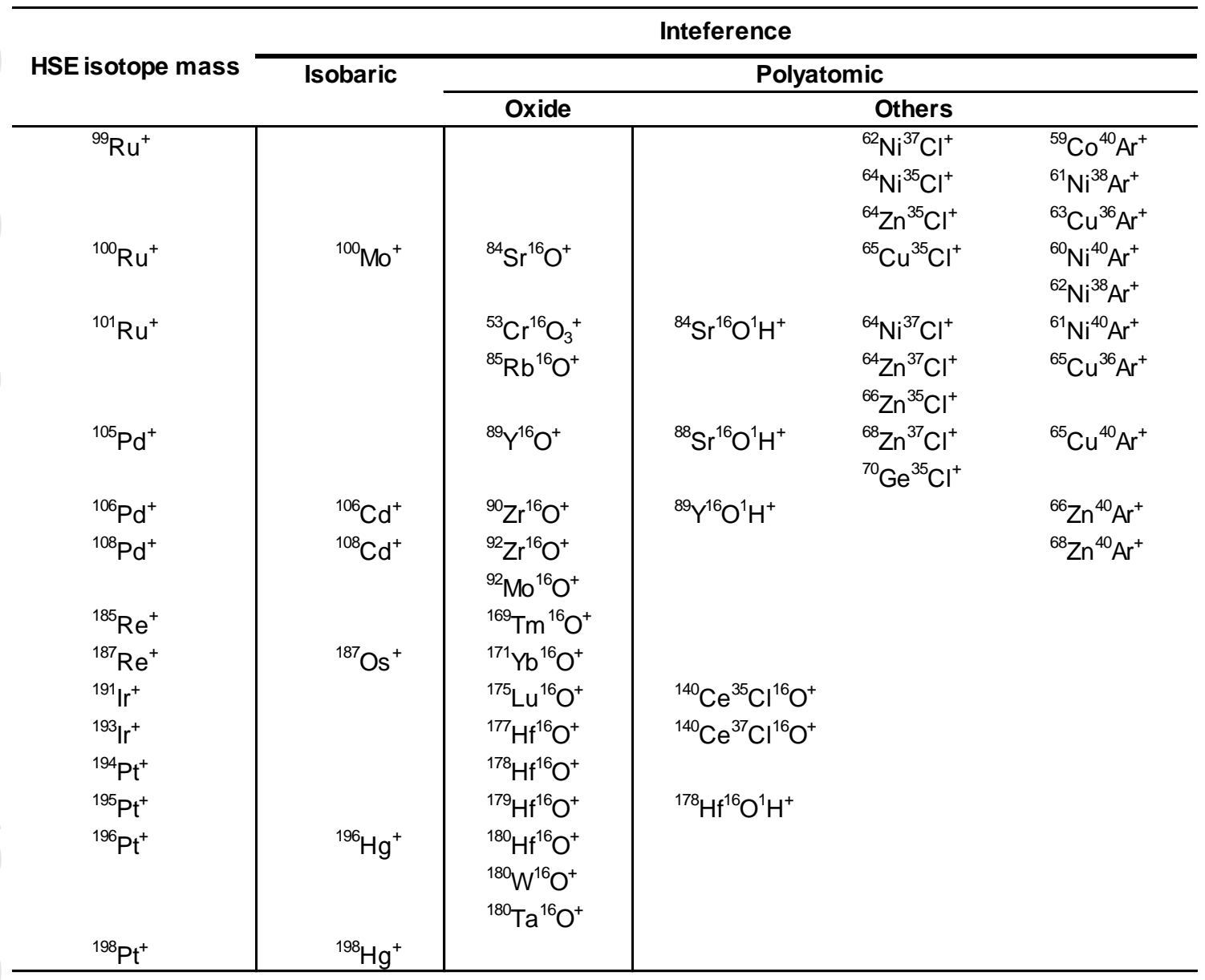

This article is protected by copyright. All rights reserved. 
Table 3.

Distribution coefficient (Kd) of HSEs and interfering elements in LN and Chelex 100 resins determined in this study

\begin{tabular}{|c|c|c|c|c|c|c|c|c|c|c|}
\hline & & Ru & Pd & $\mathbf{R e}$ & Ir & $\mathrm{Pt}$ & $\mathbf{Y}$ & $\mathrm{Zr}$ & Cd & $\mathrm{Hf}$ \\
\hline \multirow[t]{2}{*}{ LN resin } & $0.5 \mathrm{~mol} \mathrm{I}^{-1} \mathrm{HCl}$ & 1 & 0.3 & 11 & 1 & 2 & $\overline{5.4 \times 10^{2}}$ & $9 \times 10^{6}$ & 1 & $3 \times 10^{11}$ \\
\hline & $0.5 \mathrm{moll}^{-1} \mathrm{HF}$ & 7 & 7 & 8 & 3 & 5 & 20 & 2 & 6 & 7 \\
\hline \multirow[t]{3}{*}{ Chelex 100 resin } & $0.5 \mathrm{~mol} \mathrm{I}^{-1} \mathrm{HNO}_{3}$ & 6 & $1.3 \times 10^{3}$ & 20 & 8 & 14 & 0.4 & 2 & 2 & 2 \\
\hline & $0.5 \mathrm{moll}^{-1} \mathrm{HF}$ & 36 & $2.8 \times 10^{3}$ & 78 & 35 & 44 & 3 & 1 & 10 & 2 \\
\hline & $8 \mathrm{~mol} \mathrm{I}^{-1} \mathrm{HCl}$ & 4 & 8 & 30 & 5 & 26 & 2 & 7 & 18 & 7 \\
\hline
\end{tabular}

This article is protected by copyright. All rights reserved. 
Table 4.

Ratios of interference intensities relative to the measured intensities of HSE isotope masses (cps/cps in parts per million) during ICP-MS measurement

\begin{tabular}{|c|c|c|c|c|c|c|c|c|c|c|}
\hline \multirow{2}{*}{ inteference/isotope } & \multicolumn{5}{|c|}{ Non-desilicification } & \multicolumn{5}{|c|}{ Desilicification } \\
\hline & UB-N & JP-1 & MUH-1 & OKUM & TDB-1 & UB-N & JP-1 & $\mathrm{MUH}-1$ & OKUM & TDB-1 \\
\hline${ }^{53} \mathrm{Cr}^{16} \mathrm{O}_{3}{ }^{+101} \mathrm{Ru}^{+}$ & $<1$ & $<1$ & $<1$ & $<1$ & $<1$ & $<1$ & $<1$ & $<1$ & $<1$ & $<1$ \\
\hline${ }^{89} \mathrm{Y}^{16} \mathrm{O}^{+}{ }^{105} \mathrm{Pd}^{+}$ & $<1$ & $<1$ & $<1$ & $<1$ & $<1$ & $<1$ & $<1$ & $<1$ & $<1$ & $<1$ \\
\hline${ }^{90} \mathrm{Zr}^{16} \mathrm{O}^{+} /{ }^{106} \mathrm{Pd}^{+}$ & $13 \pm 2$ & $66 \pm 119$ & $3 \pm 2$ & $0.8 \pm 0.3$ & $<1$ & $18 \pm 6$ & $53 \pm 62$ & $3 \pm 1$ & $1.6 \pm 0.4$ & $<1$ \\
\hline${ }^{106} \mathrm{Cd}^{+} /{ }^{106} \mathrm{Pd}^{+}$ & $100 \pm 149$ & $172 \pm 188$ & $140 \pm 95$ & $224 \pm 153$ & $23 \pm 23$ & $47 \pm 15$ & $127 \pm 76$ & $110 \pm 25$ & $233 \pm 188$ & $249 \pm 225$ \\
\hline${ }^{177} \mathrm{Hf}^{16} \mathrm{O}^{+} / /^{193} \mathrm{rr}^{+}$ & $<1$ & $<1$ & $<1$ & $<1$ & $3 \pm 4$ & $<1$ & $<1$ & $<1$ & $<1$ & $26 \pm 20$ \\
\hline${ }^{178} \mathrm{Hf}^{16} \mathrm{O}^{+} /{ }^{194} \mathrm{Pt}^{+}$ & $<1$ & $<1$ & $<1$ & $<1$ & $<1$ & $<1$ & $<1$ & $<1$ & $<1$ & $2 \pm 2$ \\
\hline${ }^{179} \mathrm{Hf}^{16} \mathrm{O}^{+} /{ }^{195} \mathrm{Pt}^{+}$ & $<1$ & $<1$ & $<1$ & $<1$ & $<1$ & $<1$ & $<1$ & $<1$ & $<1$ & $1.5 \pm 1$ \\
\hline
\end{tabular}

Table 5.

HSE mass fractions ( $\mathrm{ng} \mathrm{g}^{-1}$ ) and Os isotopic compositions of UB-N, JP-1 and MUH-1 from this study and the literature

\begin{tabular}{|c|c|c|c|c|c|c|c|c|c|c|c|c|c|c|c|c|c|c|}
\hline \multirow{2}{*}{$\begin{array}{l}\text { UB-N (serpentinite, CRPG) } \\
\text { This study }\end{array}$} & \multirow{2}{*}{\begin{tabular}{|c} 
Digestion $^{a}$ \\
CT
\end{tabular}} & \multirow[t]{2}{*}{ No. } & \multicolumn{2}{|c|}{ Ru } & \multicolumn{2}{|c|}{$\mathbf{P d}$} & \multicolumn{2}{|c|}{$\mathbf{R e}$} & \multicolumn{2}{|l|}{ Ir } & \multicolumn{2}{|c|}{ Pt } & \multicolumn{2}{|c|}{ Os } & \multicolumn{2}{|c|}{${ }^{187} \mathrm{Re} /{ }^{188} \mathrm{Os}$} & \multicolumn{2}{|c|}{${ }^{187} \mathrm{Os}^{1{ }^{188}}$ Os } \\
\hline & & & 70 & & & & & 2 & & & & & & & & & & \\
\hline & & $\begin{array}{l}1 \\
2\end{array}$ & $\begin{array}{l}6.16 \\
6.49\end{array}$ & 10 & $\begin{array}{l}5.37 \\
5.47\end{array}$ & 8 & $\begin{array}{l}0.198 \\
0.193\end{array}$ & 2 & $\begin{array}{l}3.48 \\
2.82\end{array}$ & $\begin{array}{l}4 \\
3\end{array}$ & $\begin{array}{l}.02 \\
6.42\end{array}$ & 8 & $\begin{array}{l}3.51 \\
3.45\end{array}$ & $\begin{array}{l}5 \\
5\end{array}$ & $\begin{array}{l}0.272 \\
0.270\end{array}$ & $\begin{array}{l}5 \\
5\end{array}$ & $\begin{array}{l}0.12727 \\
0.12745\end{array}$ & $\begin{array}{l}14 \\
15\end{array}$ \\
\hline & & 3 & 6.29 & 9 & 5.51 & 8 & 0.193 & 2 & 3.32 & 4 & 6.89 & 9 & 3.35 & 5 & 0.278 & 5 & 0.12676 & 47 \\
\hline & & 4 & 6.02 & 9 & 5.44 & 8 & 0.182 & 2 & 3.37 & 4 & 7.08 & 10 & 3.27 & 5 & 0.269 & 5 & 0.12766 & 28 \\
\hline & & 5 & 5.77 & 8 & 5.70 & 7 & 0.190 & 2 & 2.55 & 2 & 6.86 & 8 & 3.02 & 4 & 0.303 & 5 & 0.12692 & 13 \\
\hline & & 6 & 6.17 & 7 & 5.85 & 11 & 0.198 & 2 & 3.05 & 3 & 7.25 & 9 & 3.41 & 5 & 0.280 & 5 & 0.12856 & 20 \\
\hline & & 7 & 5.86 & 7 & 5.67 & 11 & 0.194 & 2 & 3.39 & 4 & 7.65 & 10 & 3.47 & 5 & 0.270 & 5 & 0.12709 & 16 \\
\hline & & 8 & 6.01 & 7 & 5.84 & 10 & 0.193 & 2 & 3.06 & 3 & 7.32 & 8 & & & & & & \\
\hline & & $\begin{array}{c}\text { mean, } 1 s \\
\% \text { RSD }\end{array}$ & 6.17 & $\begin{array}{c}0.33 \\
5.4\end{array}$ & 5.61 & $\begin{array}{c}0.18 \\
3.3\end{array}$ & 0.192 & $\begin{array}{c}0.005 \\
2.6\end{array}$ & 3.13 & $\begin{array}{c}0.32 \\
10\end{array}$ & 7.06 & $\begin{array}{l}0.37 \\
5.2\end{array}$ & 3.35 & $\begin{array}{c}0.17 \\
5.0\end{array}$ & 0.278 & $\begin{array}{c}0.012 \\
4.4\end{array}$ & 0.12739 & $\begin{array}{c}0.00060 \\
0.47\end{array}$ \\
\hline & CT-HF & 1 & 6.72 & 10 & 5.62 & 8 & 0.198 & 2 & 2.94 & 3 & 6.73 & 9 & 3.09 & 4 & 0.309 & 5 & 0.12794 & 21 \\
\hline & & 2 & 6.80 & 10 & 5.51 & 8 & 0.189 & 2 & 3.84 & 5 & 6.75 & 9 & & & & & & \\
\hline & & 3 & 6.50 & 10 & 5.68 & 9 & 0.199 & 2 & 3.71 & 4 & 6.91 & 10 & 3.47 & 5 & 0.277 & 5 & 0.12671 & 12 \\
\hline & & 4 & 6.27 & 9 & 5.58 & 8 & 0.185 & 2 & 3.14 & 3 & 7.00 & 9 & 3.11 & 4 & 0.288 & 5 & 0.12707 & 1 \\
\hline & & 5 & 6.62 & 10 & 5.64 & 9 & 0.190 & 2 & 3.81 & 5 & 6.65 & 9 & 3.25 & 5 & 0.282 & 5 & 0.12686 & 21 \\
\hline & & 6 & 6.16 & 7 & 5.60 & 10 & 0.194 & 2 & 2.95 & 3 & 6.61 & 7 & 3.57 & 5 & 0.263 & 4 & 0.12676 & 31 \\
\hline & & 7 & 7.14 & 9 & 5.58 & 10 & 0.192 & 2 & 2.77 & 3 & 6.37 & 7 & & & & & & \\
\hline & & 8 & 6.66 & 8 & 5.73 & 11 & 0.196 & 2 & 3.23 & 3 & 6.75 & 8 & 3.82 & 6 & 0.248 & 4 & 0.12660 & 35 \\
\hline & & 9 & 5.54 & 6 & 5.73 & 11 & 0.193 & 2 & 2.78 & 3 & 6.77 & 8 & 3.24 & 7 & 0.287 & 7 & 0.12601 & 114 \\
\hline & & 10 & 6.25 & 7 & 5.85 & 11 & 0.187 & 2 & 2.79 & 3 & 6.78 & 8 & 3.50 & 5 & 0.258 & 4 & 0.12738 & 23 \\
\hline & & $\begin{array}{c}\text { mean, } 1 \mathrm{~s} \\
\% \text { RSD }\end{array}$ & 6.46 & $\begin{array}{c}0.44 \\
6.8\end{array}$ & 5.65 & $\begin{array}{c}0.10 \\
1.8\end{array}$ & 0.192 & $\begin{array}{c}0.005 \\
2.4\end{array}$ & 3.20 & $\begin{array}{c}0.43 \\
14\end{array}$ & 6.73 & $\begin{array}{l}0.17 \\
2.5\end{array}$ & 3.38 & $\begin{array}{c}0.25 \\
7.5\end{array}$ & 0.277 & $\begin{array}{c}0.020 \\
7.1\end{array}$ & 0.12692 & $\begin{array}{c}0.00057 \\
0.45\end{array}$ \\
\hline Ishikawa et al.(2012) & CT & $\mathrm{n}=9, \%$ RSD & 6.85 & 5.9 & 5.55 & 3.1 & 0.210 & 8.6 & 3.47 & 6.7 & 6.98 & 5.0 & 3.97 & 9.6 & 0.257 & 15 & 0.12732 & 0.67 \\
\hline & CT-H & $\mathrm{n}=4, \%$ RSD & 6.70 & 9.9 & 5.67 & 2.9 & 0.203 & 0.9 & 3.26 & 8.9 & 6.82 & 3.7 & 3.57 & 7.8 & 0.275 & 7.9 & 0.12720 & 0.40 \\
\hline Li et al. (201. & CT & $\mathrm{n}=5, \%$ RSD & 7.09 & 16 & 5.66 & 6.3 & 0.197 & 6.6 & 3.56 & 16 & 7.56 & 4.0 & 3.42 & 11 & 0.280 & 7.6 & 0.12700 & 0.16 \\
\hline Fisch & CT & & 6.52 & 6.2 & 5.85 & 3.4 & 0.201 & 5.9 & 3.33 & 5.0 & 7.55 & 5.0 & 3.70 & 8.4 & & & 0.12704 & 0.20 \\
\hline Becker et al. (2006 & CT & $n=4, \%$ RSD & 6.51 & 5.0 & 5.86 & 4.5 & 0.205 & 1.9 & 3.26 & 4.0 & 7.00 & 3.2 & 3.51 & 3.6 & 0.282 & 5.1 & 0.12737 & 0.25 \\
\hline Luguet $€$ & CT & $\mathrm{n}=6, \%$ RSD & 6.48 & 4.5 & 6.17 & 4.1 & 0.205 & 3.4 & 3.24 & 10 & 8.07 & 14 & 3.66 & 4.1 & & & 0.12790 & 0.39 \\
\hline Puchtel et al. (2008) & CT & $\mathrm{n}=4, \%$ RSD & 6.93 & 3.4 & 5.70 & 1.1 & 0.213 & 2.6 & 3.58 & 5.6 & 7.47 & 1.1 & 3.85 & 4.2 & & & 0.1272 & 0.15 \\
\hline Kogiso et al. (200 & c & $\mathrm{n}=3, \% \mathrm{RSD}$ & 6.23 & 1.0 & 6.05 & 1.3 & 0.190 & 1.1 & 3.38 & 1.0 & 7.40 & 2.7 & 3.56 & 2.6 & & & & \\
\hline Fischier et al. (2011 & HPA & $\mathrm{n}=11, \%$ RSD & 6.36 & 5.7 & 5.86 & 3.5 & 0.184 & 14 & 3.02 & 5.0 & 7.16 & 6.5 & 3.46 & 5.7 & 0.257 & 13 & 0.12729 & 0.20 \\
\hline Meisel and Moser (2004b) & HPA & $n=14, \% R S D$ & 6.30 & 4.6 & 6.11 & 2.9 & 0.206 & 2.4 & 3.38 & 6.4 & 7.42 & 4.0 & 3.71 & 7.2 & & & & \\
\hline
\end{tabular}

This article is protected by copyright. All rights reserved. 


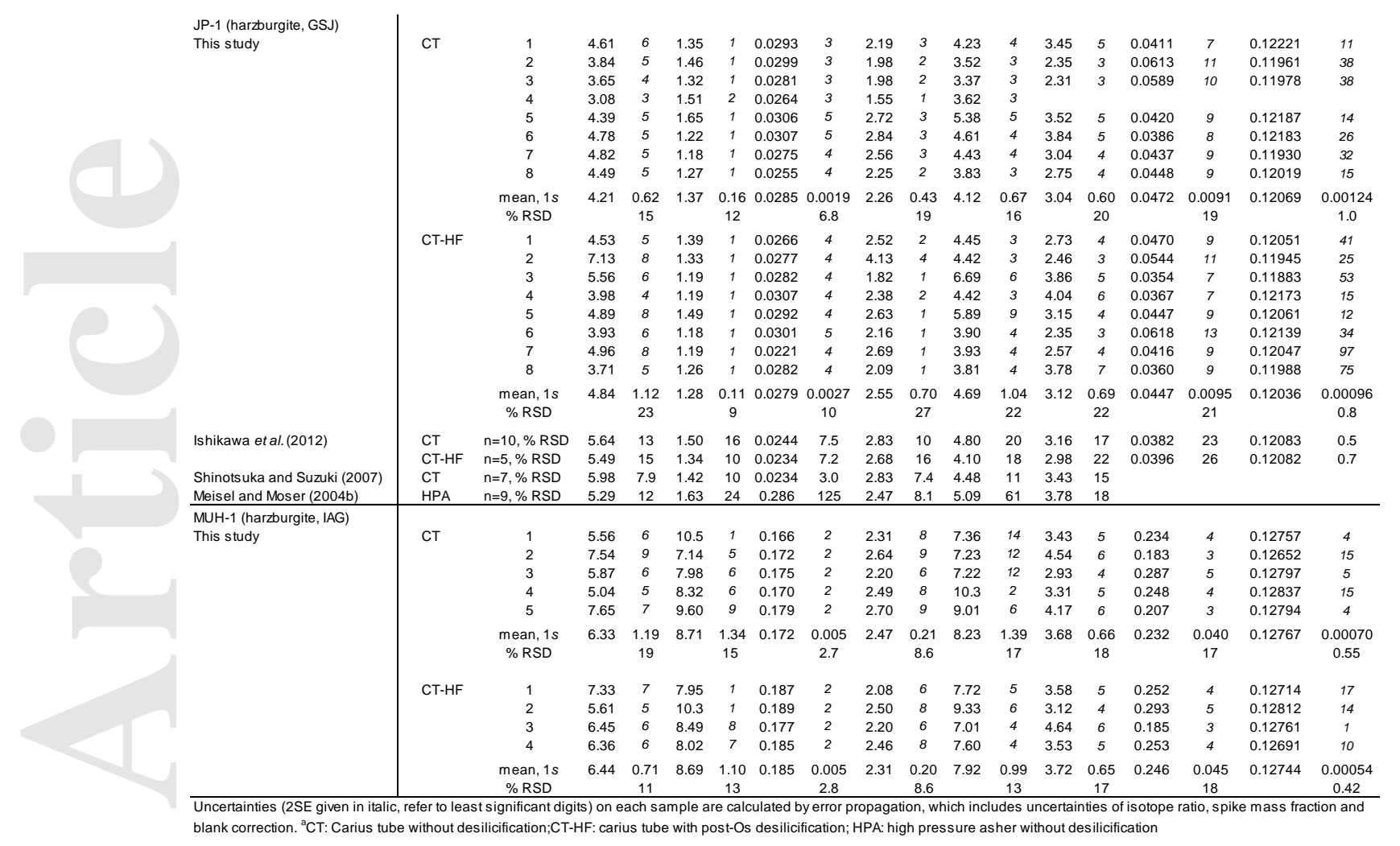

Table 6.

HSE mass fractions $\left(\mathrm{ng} \mathrm{g}^{-1}\right)$ and Os isotopic compositions of OKUM and TDB-1 from this study and the literatur

\begin{tabular}{|c|c|c|c|c|c|c|c|c|c|c|c|c|c|c|c|c|c|c|}
\hline OKUM (komatiite, IAG) & \begin{tabular}{|l|} 
Digestion $^{\mathrm{a}}$ \\
\end{tabular} & No. & \multicolumn{2}{|c|}{$\mathbf{R u}$} & \multicolumn{2}{|c|}{$\mathbf{P d}$} & \multicolumn{2}{|c|}{$\mathrm{Re}$} & \multicolumn{2}{|c|}{ Ir } & \multicolumn{2}{|c|}{$\mathrm{Pt}$} & \multicolumn{2}{|c|}{ Os } & \multicolumn{2}{|c|}{${ }^{187} \mathrm{Re} /{ }^{188}$ Os } & \multicolumn{2}{|c|}{${ }^{187}$ Os/ ${ }^{188}$ Os } \\
\hline \multirow{11}{*}{ This study } & CT & 1 & 4.04 & 4 & 11.1 & 1 & 0.454 & 4 & 0.776 & 9 & 10.3 & 2 & 0.765 & 11 & 2.87 & 5 & 0.2642 & \\
\hline & & 2 & 3.93 & 4 & 11.4 & 1 & 0.445 & 4 & 0.790 & 8 & 9.99 & 20 & 0.767 & 11 & 2.80 & 5 & 0.2629 & 3 \\
\hline & & 3 & 3.99 & 4 & 12.6 & 1 & 0.472 & 5 & 0.784 & 9 & 10.1 & 2 & 0.780 & 11 & 2.92 & 5 & 0.2632 & 6 \\
\hline & & 4 & 4.04 & 4 & 10.5 & 1 & 0.462 & 5 & 0.763 & 8 & 10.2 & 2 & 0.737 & 10 & 3.03 & 5 & 0.2741 & 3 \\
\hline & & 5 & 3.86 & 4 & 10.7 & 1 & 0.450 & 4 & 0.730 & 8 & 10.4 & 2 & 0.696 & 10 & 3.12 & 5 & 0.2791 & 3 \\
\hline & & $\begin{array}{c}\text { mean, } 1 s \\
\% \text { RSD }\end{array}$ & 3.97 & $\begin{array}{c}0.08 \\
1.9\end{array}$ & 11.3 & $\begin{array}{c}0.83 \\
7.3\end{array}$ & 0.456 & $\begin{array}{c}0.011 \\
2.4\end{array}$ & 0.769 & $\begin{array}{c}0.024 \\
3.1\end{array}$ & 10.2 & $\begin{array}{l}0.1 \\
1.4\end{array}$ & 0.749 & $\begin{array}{c}0.034 \\
4.5\end{array}$ & 2.95 & $\begin{array}{c}0.13 \\
4.3\end{array}$ & 0.2687 & $\begin{array}{c}0.0074 \\
2.8\end{array}$ \\
\hline & CT-HF & 1 & 4.40 & 4 & 11.2 & 1 & 0.493 & 5 & 1.02 & 1 & 11.5 & 1 & 0.962 & 13 & 2.47 & 4 & 0.2302 & 3 \\
\hline & & 2 & 4.45 & 4 & 11.6 & 1 & 0.502 & 5 & 0.847 & 10 & 11.8 & 1 & 0.669 & 9 & 3.62 & 6 & 0.2912 & 3 \\
\hline & & 3 & 4.32 & 4 & 11.7 & 1 & 0.466 & 5 & 0.907 & 12 & 11.5 & 1 & 0.778 & 11 & 2.89 & 5 & 0.2576 & 2 \\
\hline & & 4 & 4.40 & 4 & 10.6 & 1 & 0.459 & 5 & 1.02 & 1 & 11.3 & 1 & 1.01 & 1 & 2.19 & 4 & 0.2266 & 1 \\
\hline & & $\begin{array}{c}\text { mean, } 1 s \\
\% \text { RSD }\end{array}$ & 4.39 & $\begin{array}{c}0.05 \\
1.2\end{array}$ & 11.3 & $\begin{array}{l}0.5 \\
4.4\end{array}$ & 0.480 & $\begin{array}{c}0.021 \\
4.3\end{array}$ & 0.951 & $\begin{array}{c}0.088 \\
9.3\end{array}$ & 11.5 & $\begin{array}{l}0.2 \\
1.7\end{array}$ & 0.855 & $\begin{array}{c}0.160 \\
19\end{array}$ & 2.80 & $\begin{array}{c}0.62 \\
22\end{array}$ & 0.2514 & $\begin{array}{c}0.0299 \\
12\end{array}$ \\
\hline Savard et al. (2010) & HPA & mean, $\%$ RSD & 4.15 & 2.0 & 12.20 & 6.0 & 0.566 & 6.3 & 0.943 & 3.9 & 11.44 & 1.9 & 0.790 & & & & & \\
\hline Wang and Becker (2014) & HPA & $n=6, \%$ RSD & 4.44 & 2.0 & 11.8 & 4.0 & 0.4 & 21 & 0.897 & 8.0 & 21.1 & 46 & 3.61 & 97 & & & 0.4185 & 35 \\
\hline
\end{tabular}

This article is protected by copyright. All rights reserved. 


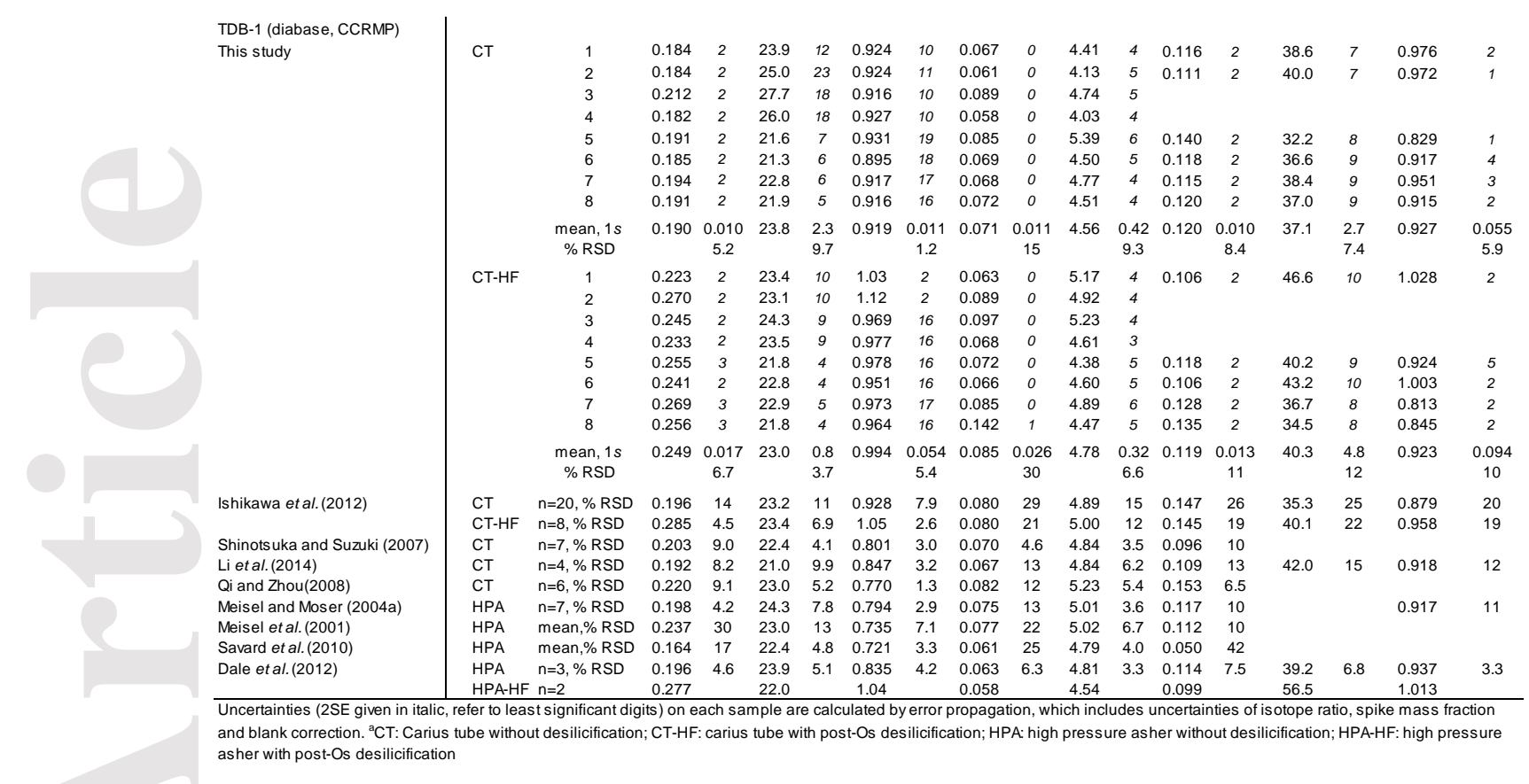

This article is protected by copyright. All rights reserved. 


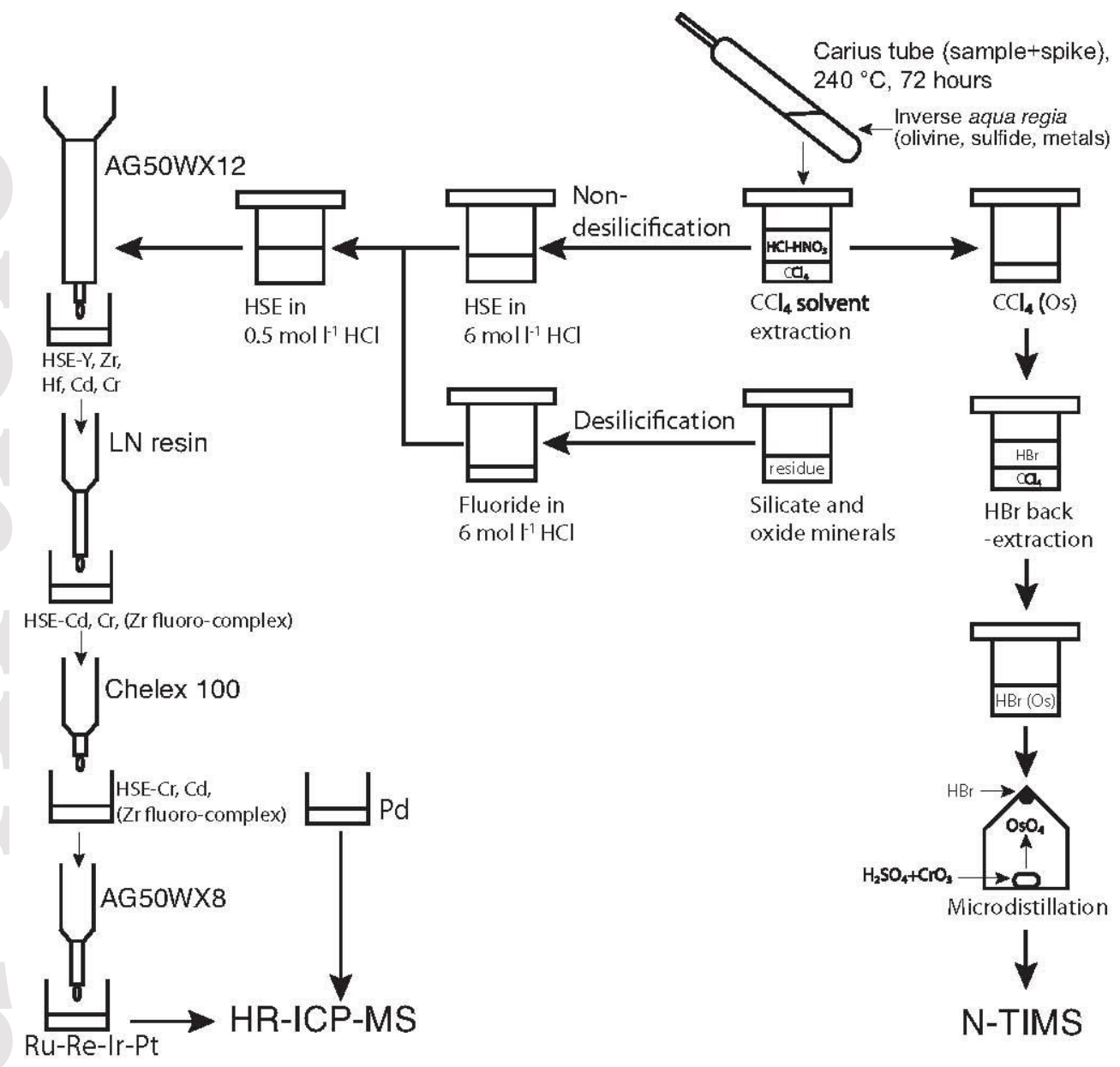

This article is protected by copyright. All rights reserved. 


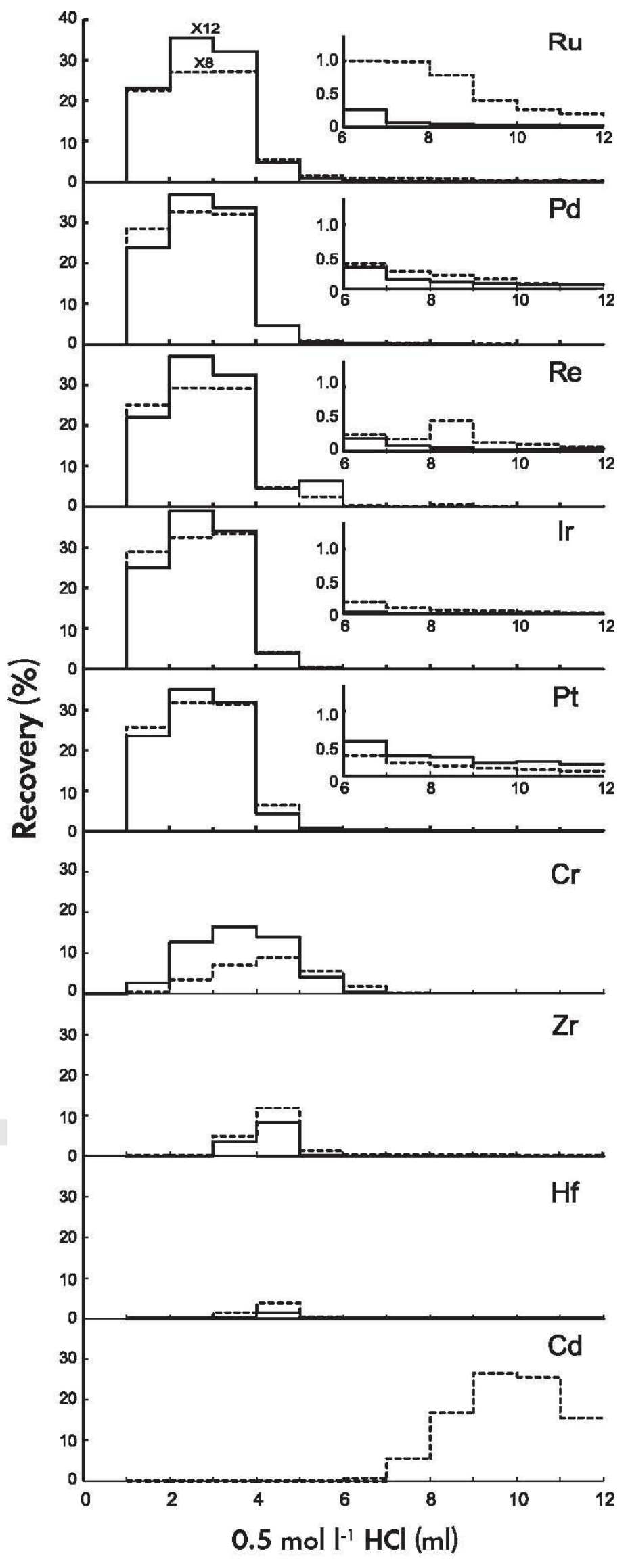

This article is protected by copyright. All rights reserved. 

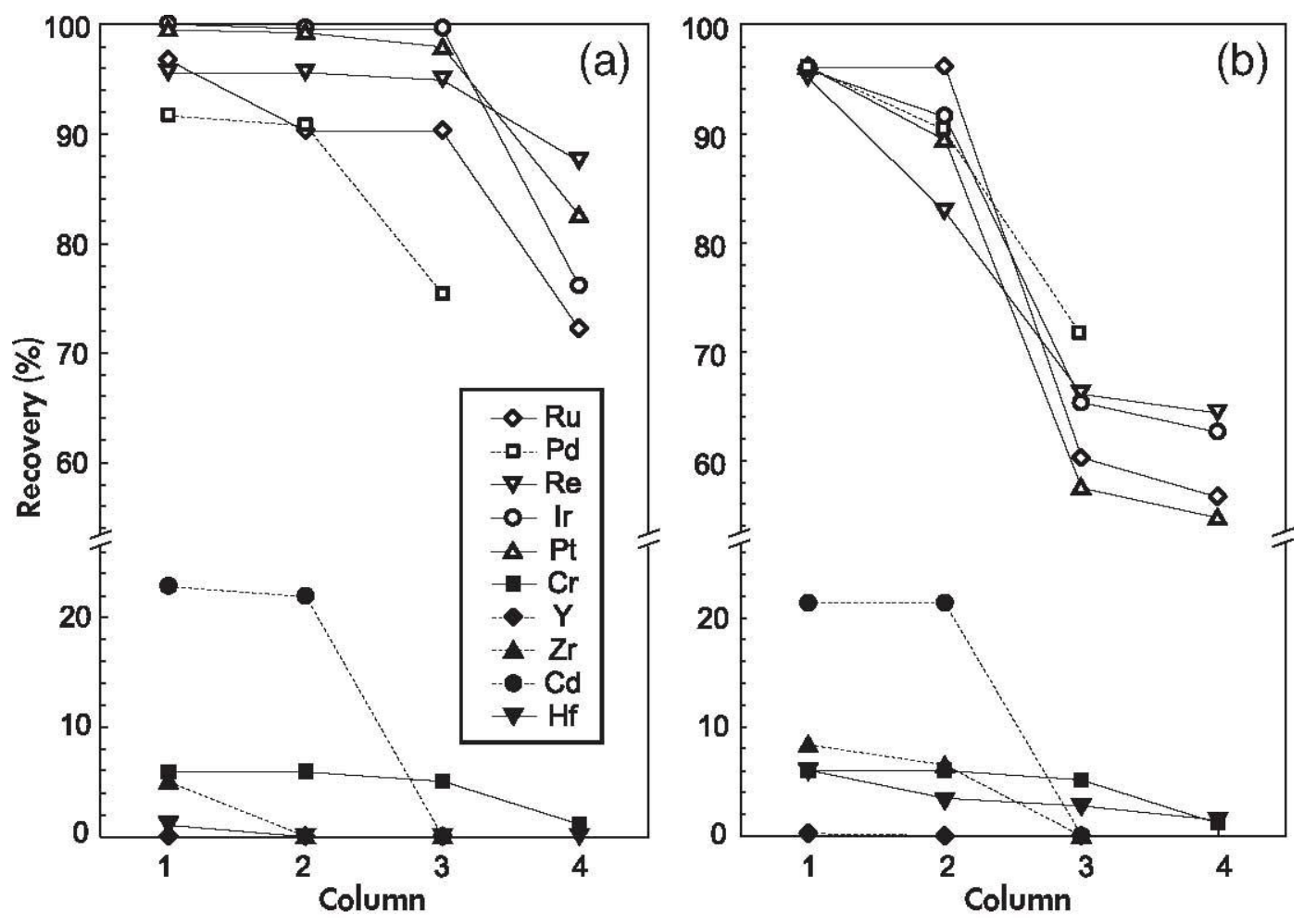

This article is protected by copyright. All rights reserved. 

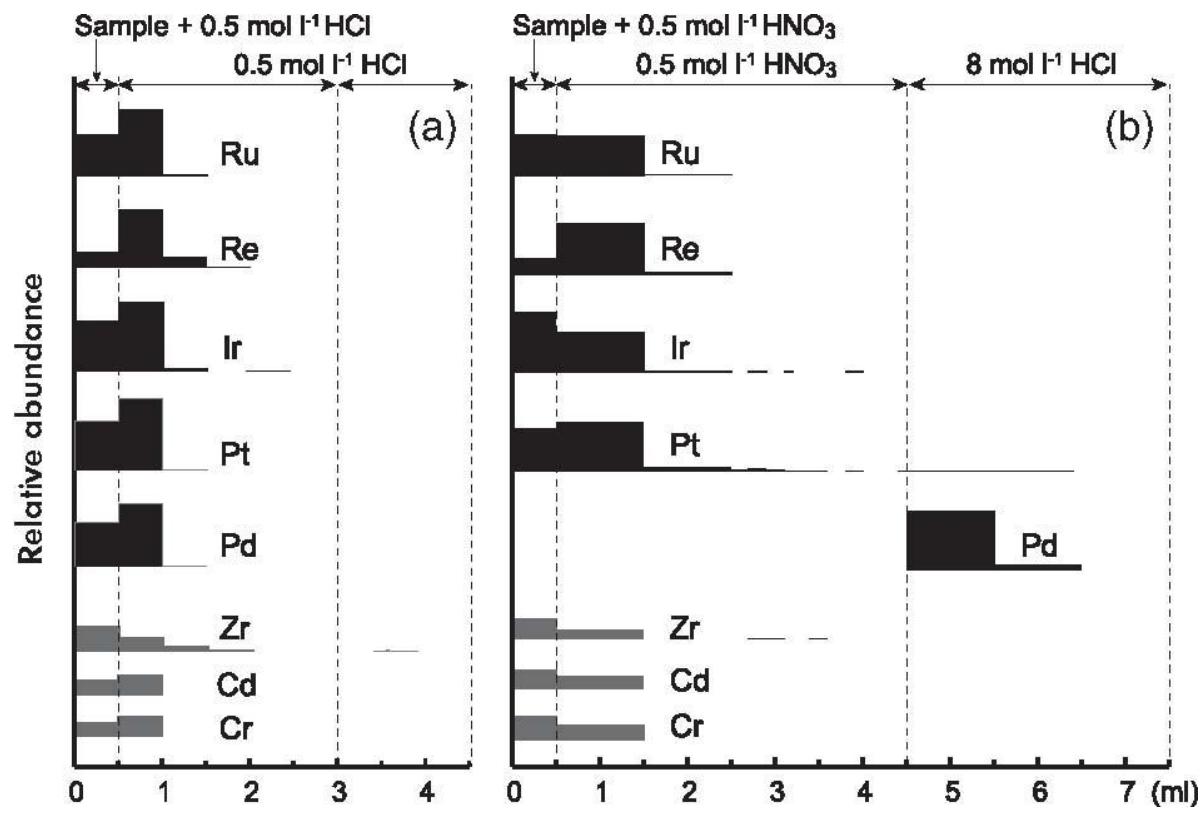

This article is protected by copyright. All rights reserved. 


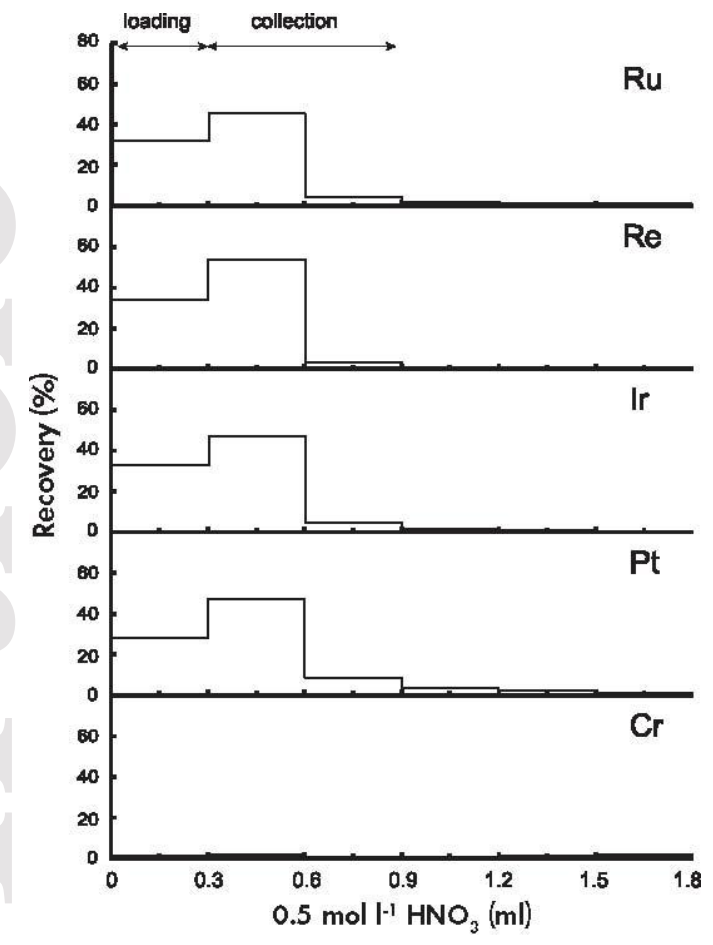

This article is protected by copyright. All rights reserved. 


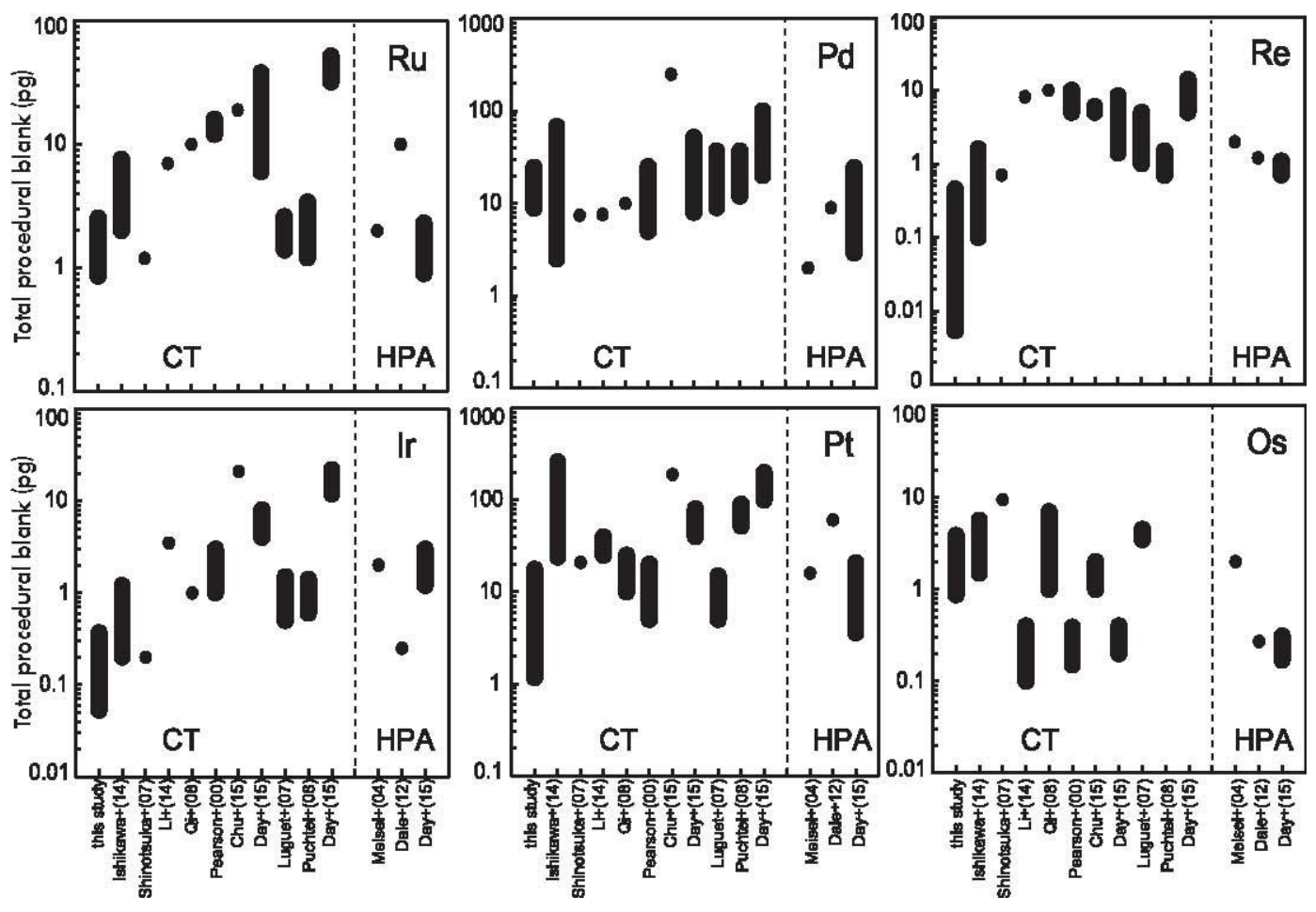

This article is protected by copyright. All rights reserved. 
(a) UB-N

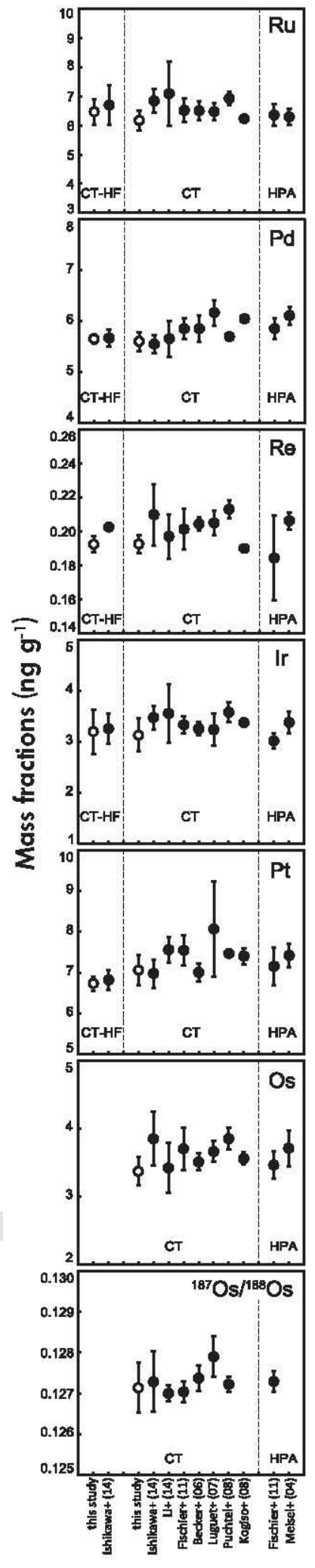

(b) JP-1

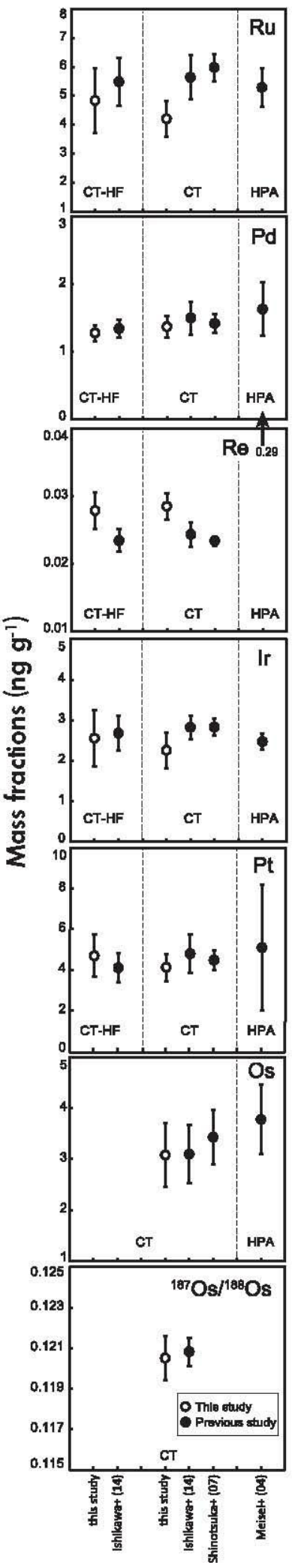

(c) TDB-1

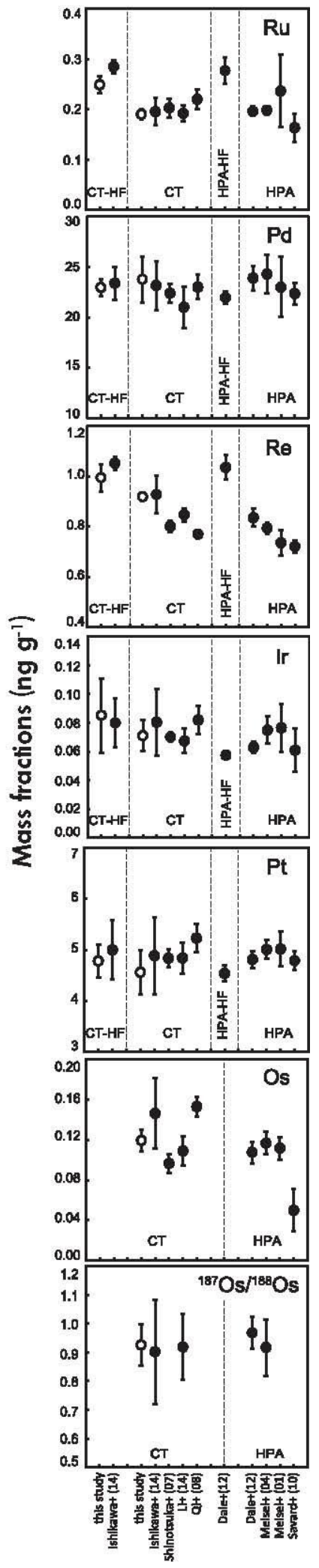

This article is protected by copyright. All rights reserved. 


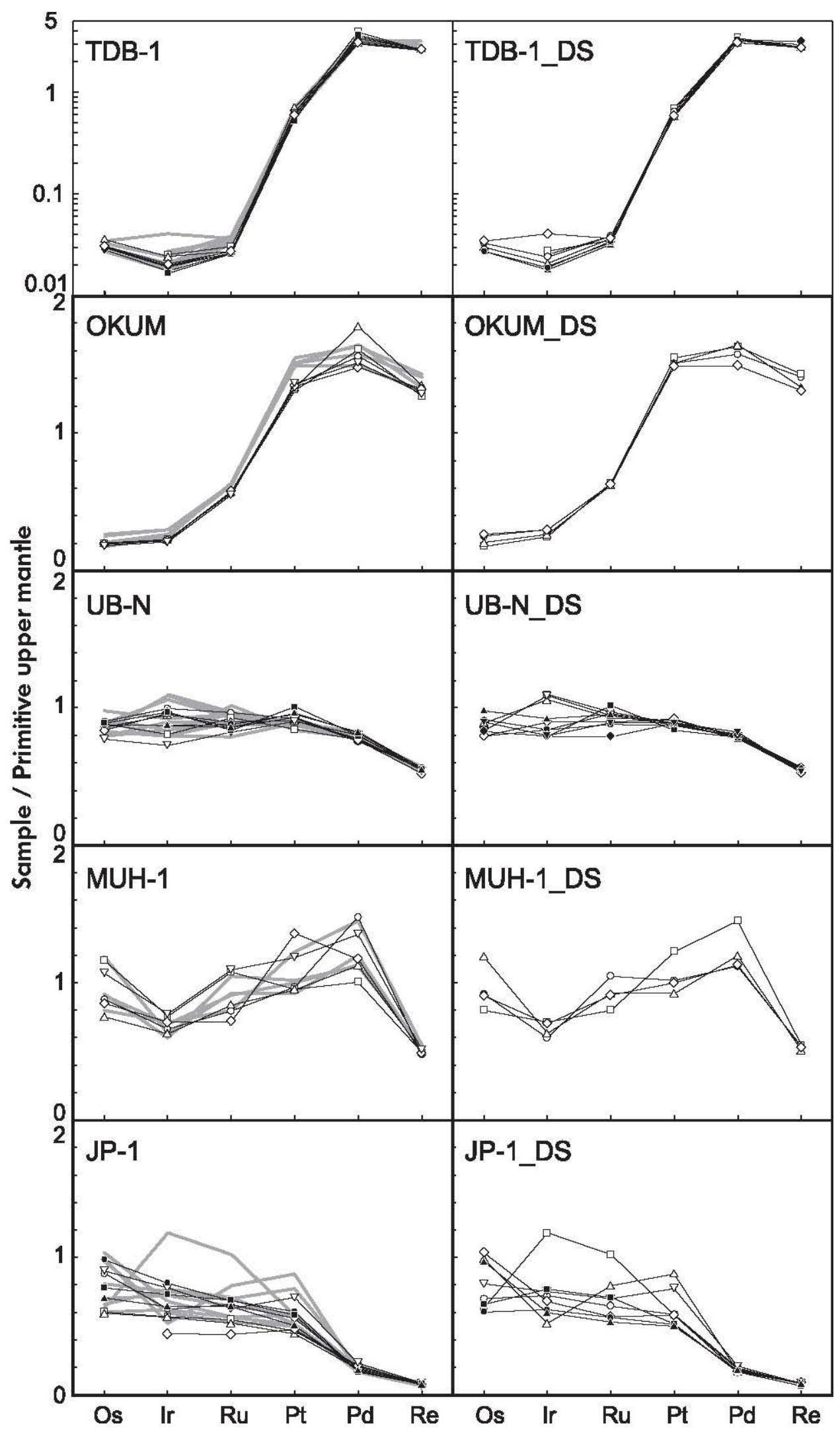

This article is protected by copyright. All rights reserved. 